\title{
Protocolo y ceremonial en la comunidad judía
}

\section{Protocol and ceremonial in the jewish community}

\author{
Enrique Somavilla Rodríguez ${ }^{1}$ \\ Centro Teológico San Agustín - CTSA \\ enrisom@gmail.com \\ Recepción: 10/09/2020 Revisión: 19/11/2020 Aceptación: 27/11/2020 Publicación: 01/12/2020
}

\begin{abstract}
Resumen
La religión judía ha vuelto a tener nuevos adeptos en los jóvenes como consecuencia de no tener referentes en sus inmediatos mayores una expresión profunda de la fidelidad que tuvo siempre el Pueblo de Israel por su Dios: Yahvé. Probablemente toda la historia del pueblo judío, ha atravesado a través de la historia por innumerables y desgraciados acontecimientos que han marcado su vida: desde la salida de la esclavitud de Egipto, comandados por Moisés, guiados por la mano del Señor, durante cuarenta años hasta la llegada a la Tierra prometida, hasta los hechos lamentables, desgraciados que desembocaron en la persecución y exterminio en los campos de concentración nazis durante la década de los 30 y 40 del siglo XX, conocida por todos como la Shoá. Éste, sin duda, puede haber uno de los aspectos que ha incidido hacia una mayor religiosidad en las generaciones actuales.
\end{abstract}

Palabras clave: Protocolo, judaísmo, sionismo, precedencia, tratamiento.

${ }^{1}$ Es doctor en Teología Dogmática y en Derecho, licenciado en Estudios Eclesiásticos, Máster en Doctrina Social de la Iglesia, Máster en Relaciones Internacionales y Protocolo, Máster en Derecho de la Unión Europea, Diploma de Estudios Avanzados en Derecho (DEA). Es Profesor ordinario de Teología en el Centro Teológico San Agustín CTSA (afiliado a la Pontificia Universidad de Salamanca), donde imparte diversas asignaturas: Análisis Político y Económico, Sacramentos de Iniciación cristiana, Misterio de Dios, Cristología, Iglesias Orientales, Ecumenismo, Doctrina social de la Iglesia. Profesor de Teología cristiana de las religiones: relaciones interreligiosas, Teología de la Comunicación, en el Estudio Teológico Agustiniano de Valladolid ETAV (Centro Agregado a la Facultad de Teología del Norte, sede de Burgos). Profesor de Derecho Eclesiástico del Estado en El Real Centro Universitario Escorial-María Cristina, en San Lorenzo de El Escorial (Madrid) adscrito a la Universidad Complutense. 


\begin{abstract}
The Jewish Religion has had new young adepts once again as the result of the lack of references from their immediate seniors on a deep expression of the characteristic faithfulness of the People of Israel for their God: Yahweh. It is probable that all the history of the Jewish people, which has passed through a great number of unfortunate moments in history, has leaved a mark in their lives: from the exile of the slavery in Egypt, leaded by Moses and guided by God's hand during forty years until they arrived to the promised land, until the lamentable and unfortunate facts that ended in their persecution and extermination in the Nazis Concentration Camps during the decades of the 30's and 40's of the twenty century, event known as shoa. This fact, without doubt, can be considered one of the main aspects in the growth of a greater religiosity in nowadays generations.
\end{abstract}

Keywords: Protocol, Judaism, Zionism, precedence, treatment.

0. Introducción

1.Protocolo, Historia y desarrollo de la religión judía

2.Elementos para el protocolo judío

3.Ceremonial sobre el nacimiento

4.Celebración del matrimonio en la religión judía

5. Entierro o Keruva

6. Concepción espiritual del judaísmo

7.La Sinagoga

8.Indumentaria religiosa en el mundo judío

9.Tratamientos en la religión judía

10. Balance

11. Conclusión

\title{
0. Introducción
}

Se puede partir de la idea que la religión judía es una de las más antiguas que mantiene plena vigencia en la actualidad. El judaísmo es la religión del pueblo judío y comprende un sistema de creencias, doctrinas, ritos y costumbres que fueron sistematizados en una amplia literatura, a partir del siglo I d. C. Sin embargo, el origen del judaísmo es ciertamente anterior y se remonta hacia dos milenios antes de Cristo. Los judíos creen en un solo Dios, quién reveló 
la ley a su pueblo. Descendientes de aquellos antiguos hebreos, Abraham². Después llegarían Isaac Esaú, Jacob, Moisés, el período de los reyes, David y Salomón, los profetas desde Isaías a Zacarías ${ }^{3}$. El Tanakh es el nombre de la Biblia judía en donde se cuenta la historia del pueblo hebreo. Su parte más importante es la Torá o Torah, cuyos primeros cinco libros incluyen las leyes y los diez mandamientos que Dios le reveló a Moisés, que nosotros conocemos como el Pentateuco.

Las reglas y rituales más importantes de la tradición judía son: la realización de la circuncisión a los niños a los ocho días del nacimiento; el Shabbat (sábado) es el día Sagrado, dedicado al descanso y al reposo; los tabúes alimenticios como la carne de cerdo y la ceremonia de iniciación al período adulto a los 13 años, llamado Bar-Mitzvah. En el judaísmo existen diversas corrientes o variantes: se considera que, de los aproximadamente 14 millones de judíos actuales, son descendientes de los sefardíes el 5\%, orientales el $10 \%$ y los askenazíes, provenientes del centro y este de Europa, el $85 \%$. Pero en la práctica, existen distintos y muy diferentes formas de judaísmo que han dado la posibilidad de situarse en el plano religioso desde distintos puntos de vista, tales como judaísmo ortodoxo, conservador, progresista, reconstruccionista y reformista ${ }^{4}$ :

JUDAÍSMO ORTODOXO: El judaísmo ortodoxo sostiene que la Torá constituye una unidad inagotable, autoridad vinculante de todos los aspectos de la vida de un judío. Gran parte de los judíos ortodoxos desconocen al Estado de Israel por ser un estado secular. Y otra parte de esta línea, se preparan para una era mesiánica.

JUDAÍSMO CONSERVADOR: El judaísmo conservador surgió frente a las reformas radicales del judaísmo reformista hacia fines del siglo XIX. El objetivo era permitir la adaptación al mundo moderno sin dejar de conservar la legislación bíblica y talmúdica. Buscaron conservar el hebreo en la liturgia.

JUDAÍSMO PROGRESISTA O LIBERAL: Desarrollado en Europa y en América, incorpora aspectos diferentes en las creencias y en la práctica y es un heredero del judaísmo reformista.

JUDAÍSMO RECONSTRUCCIONISTA: Esta variante, representada por el Colegio Rabínico Reconstruccionista de Filadelfia, enfatiza el judaísmo como una civilización religiosa evolución. Filosofía, teología y sociología se combinan desapareciendo el teísmo sobre natural o la Torá

\footnotetext{
${ }^{2}$ Cf. D. GIRA, Las religiones, Bilbao 1994, pp. 42-44.

${ }^{3}$ Cf. H. KüNG, El judaísmo. Pasado, presente y futuro, Madrid 2013.

${ }^{4}$ Cf. B. SORJ, Judaísmo para todos, Río de Janeiro 2011, pp. 45-62.
} 
como revelación divina e inmutable. La creencia en Dios remite a un sentido de dependencia de los poderes del universo.

JUdAísMO REFORMISTA: Comenzó en Alemania a fines del siglo XIX con el objeto de proponer una reforma del culto, ritual y creencias. El movimiento enfatiza la experiencia, la ética de los profetas y la fe. Hombres y mujeres se sientan juntos en el templo y ellas no se cubren la cabeza. También admiten el trabajo en el Shabbat ${ }^{5}$.

El aumento de las conversiones está ampliando el incipiente censo de judíos en España. Se calcula aproximadamente que en nuestro país hay entre 40.000 y 50.000 judíos, mayoritariamente ortodoxos. El asunto de la conversión, precisamente, es uno de los grandes problemas de fondo del judaísmo, ya que sus tres principales ramas, ortodoxa, conservadora y reformista, nunca han logrado ponerse de acuerdo en los requisitos necesarios ${ }^{6}$. En todos los casos se destaca que siempre suele ser una búsqueda muy personal, que va unida a los cambios sociales producidos en nuestro país y en los más jóvenes la necesidad de buscar una dimensión religiosa que nunca han practicado.

\section{PROTOCOLO, HISTORIA Y DESARROLLO DE LA RELIGIÓN JUDÍA}

Existe un vínculo espiritual entre judaísmo y cristianismo y de la forma que los creyentes viven auténticamente su fe. Sin duda, se trata de algo muy esencial.

"Al investigar el misterio de la Iglesia, este Sagrado Concilio recuerda los vínculos con que el Pueblo del Nuevo Testamento está espiritualmente unido con la raza de Abraham. Pues la Iglesia de Cristo reconoce que los comienzos de su fe y de su elección se encuentran ya en los Patriarcas, en Moisés y los Profetas, conforme al misterio salvífico de Dios. Reconoce que todos los cristianos, hijos de Abraham según la fe, están incluidos en la vocación del mismo Patriarca y que la salvación de la Iglesia está místicamente prefigurada en la salida del pueblo elegido de la tierra de esclavitud.

Por lo cual, la Iglesia no puede olvidar que ha recibido la Revelación del Antiguo Testamento por medio de aquel pueblo, con quien Dios, por su inefable misericordia se dignó establecer la Antigua Alianza, ni puede olvidar que se nutre de la raíz del buen olivo en que se han injertado las ramas del olivo silvestre que son los gentiles. Cree, pues, la Iglesia que Cristo,

${ }^{5} \mathrm{Cf}$. http://religionjudia.idoneos.com/ Visto 31-01-2016.

6 Cf. http://www.elconfidencial.com/sociedad/2016-01-31/los-nuevos-hijos-de-israel-asi-se-formanlos-judios-conver Visto 31-01-2016. 
nuestra paz, reconcilió por la cruz a judíos y gentiles y que de ambos hizo una sola cosa en sí mismo"7.

Toda la Torah contiene toda la doctrina teológica y moral imprescindible de la religión y observancia judía. La Torah es el Pentateuco. La Torah comienza con el libro del Génesis donde se narran los comienzos de la humanidad ${ }^{8}$. La vida cotidiana de los judíos se regula por una perceptiva minuciosa detallada de 613 preceptos, de ellos 248 son positivos y 365 negativos. Es muy difícil y complicado poder llevar adelante todos los preceptos tal cual son. El judaísmo se basa en el Antiguo Testamento. El Talmud específica el orden y la ubicación que tienen las personas dentro del ceremonial religioso. El gran Rabino es la cabeza visible de la comunidad judía. Rabino quiere decir Maestro. Al huésped se le sitúa, dentro del templo en un lugar preferente. La sinagoga es el lugar de oración y carece de estrado para colocar personas importantes. Sinagoga viene de la palabra griega synagogé, o lugar de acogida, y el centro de reunión y culto de judaísmo. El culto de la sinagoga no es sacrificial, sino de lectura, oración y prédica. En el judaísmo ortodoxo, el hombre y la mujer se sientan en lugares separados en la sinagoga. El hombre se cubre la cabeza dentro de la sinagoga con la kippá y la mujer no puede llevar pantalones ni vestidos sin mangas. El Talmud que en hebreo literalmente significa estudio, es una obra que recoge las discusiones rabínicas sobre leyes judías, tradiciones, costumbres, leyendas e historias. El judaísmo considera al Talmud, al libro de Profetas llamados Neviim y al libro de Escritos, denominados (Ketuvim) como perteneciente a la tradición oral, mientras que la Torah o Pentateuco es solo la tradición escrita. El Talmud está dividido en dos partes, la Mishná y la Guemará. El sistema de redacción del Talmud consiste en una serie de comentarios, la Mishná, de toda la Torah, verso a verso. Los comentarios de diferentes rabinos se van sucediendo e incluso llegan a contradecirse, son auténticas discusiones sobre la ley, la ciencia, y diferentes temas sobre el conocimiento humano.

La Guemará son los ejemplos que acompañan en parte a la Mishná para la mejor comprensión, es la parte más literaria del Talmud ${ }^{9}$. Son pequeñas historias sobre los personajes bíblicos, algunas de ellas de gran belleza literaria ${ }^{10}$. La Mishná y la Guemará estudiadas o editadas juntas en una misma página es lo que llamamos Talmud. Éste se convirtió en el texto básico creado en el período rabínico y aparece como texto fundacional del curriculum de estudio judío. De aquí que los judíos tengan dos Talmud: uno escrito por los judíos que estaban en Israel y otro por los judíos que vivían en Babilonia. El Talmud editado

\footnotetext{
${ }^{7}$ Cf. Concilio Vaticano II, “Declaración Nostra Aetate”, 4, en AAS 58 (1966) 742.

${ }^{8}$ Cf. EquiPo de RedACCIÓn PAL, Historia de las religiones, Bilbao 1980, p. 218.

${ }^{9}$ Cf. S. PH. De VRIES, Ritos y símbolos judíos, Madrid 2007², pp. 287-296.

${ }^{10}$ Cf. Equipo de Redacción PaL, Historia de las religiones, Bilbao 1980, pp. 218-219.
} 
en Israel o Palestina se llama Talmud lerushalmi y el otro editado en Babilonia se llama como ya dijimos Talmud Babli. Debido a que la condición social de los rabinos en Babilonia era mejor que la de sus colegas en Jerusalén constantemente atacada y en peligro, el Talmud de Babilonia termina siendo más elaborado y más completo ${ }^{11}$.

\section{ELEMENTOS PARA EL PROTOCOLO JUDÍO}

TALIT: Manto de plegaria que se coloca el judío durante las oraciones de la mañana. El Talit es una prenda rectangular de lana o seda, con un galón a veces bordado con hilos de plata u oro en la parte superior, que rodea el cuello ${ }^{12}$. De las cuatro puntas cuelgan flecos del mismo material del Talit, Esos flecos llamados, Tzitzit, se fijan en obediencia a las prescripciones bíblicas que encontramos en el Shemá ${ }^{13}$.

TEFILIN: Los tefilin son dos cajitas de cuero casher que contienen los cuatro versículos del Pentateuco donde se habla del deber de ponerse las filacterias. Se colocan los tefilin los varones a partir del Bar Mitzvá. Una de las cajitas se coloca sobre el brazo izquierdo, frente al corazón, fuente de las emociones ${ }^{14}$. La segunda caja se coloca sobre la cabeza, arriba de la frente, descansando sobre el cerebro. De este modo, nuestra atención se dirige a la cabeza, el corazón y la mano, enseñándonos a consagrarnos al servicio de Dios en todo lo que pensamos, sentimos y hacemos ${ }^{15}$.

Menorá: Candelabro de siete brazos. Moisés bajo la dirección de Dios recibió el mandato de confeccionar una Menorá de oro puro que debía ser colocado en el tabernáculo (Ex. 25:31-40). Sobre el significado espiritual de la Menorá, los siete brazos representan la perfección de Dios, ya que el número siete en las Escrituras es el número de la perfección. La luz de la Menorá representa la perfecta y eterna luz de Dios. También se atribuyen a la Menorá diferentes simbolismos, como que representa a los siete días de la creación. En la Kabalá (mística judía) simboliza el árbol de la vida.

MezuzA: Es el símbolo que identifica una casa judía. Consiste en un pequeño tubo o cajita de material variado (madera, metal, etc.) llamado porta mezuzá, que contiene en su

11 Cf. http://www.judiosyjudaismo.com/2013/01/la-importancia-de-entender-que-es-la-literaturarabinica-mishna-guemara-talmud-y-midrash/ Visto 31-01-2016.

${ }^{12}$ Cf. J. NEWMAN - G. SivÁN, Judaísmo de A-Z. Léxico ilustrado de términos y conceptos, Jerusalén 1983.

${ }^{13}$ Cf. J. CARo, Síntesis del Shulján Aruj, Buenos Aires 1968.

${ }^{14}$ Cf. J. NeWMAN - G. SivÁN, Judaísmo de A-Z. Léxico ilustrado de términos y conceptos, Jerusalén 1983.

${ }^{15}$ Cf. J. CARO, Síntesis del Shulján Aruj, Buenos Aires 1968. 
interior, diferentes oraciones, escrito sobre un «klaf» (fina lámina de cuero labrado de animal kasher). En el exterior se escriben las letras SH-D-I (Shadai), uno de los nombres del Dios de Israel al que se da el siguiente significado: shomer (cuida), dlatot (puertas) Israel (de los Israelitas). Todo ello se coloca en el dintel de la puerta de entrada de los hogares y locales judíos, del lado derecho e inclinado oblicuamente.

KIPÁ: Uno de los símbolos más conocidos. Aún aquellos que no saben mucho acerca del judaísmo conocen el hecho de que para entrar al templo hay que cubrirse la cabeza con un solideo o kipá, o como decían en Rusia y Polonia larmulke o nombre de la kipá en ídish ${ }^{16}$. Los hombres y aún los niños la usan. Las hay bordadas, tejidas, lisas, negras o en colores. Tienen distintos significados, sobre todo en el ámbito ortodoxo ${ }^{17}$. No encontramos la kipá en fuentes bíblicas ni talmúdicas. Sólo está como antecedente la mitznefet o turbante, que el Kohen Gadol o Sumo sacerdote, debía colocarse sobre la cabeza. Por eso Levítico 8, 9, la kipá es una costumbre o minhag, y no una ley. Pero la fuerza de la tradición la instaló como si fuera esto último ${ }^{18}$.

KETUBA: La palabra Ketubá significa literalmente lo que está escrito. Es un contrato que el hombre hace con la mujer donde declara que cumplirá con sus obligaciones como marido, según la ley y la tradición judías. La Ketubá debe estar en manos de la mujer o su representante. Si se pierde hay que redactar una nueva; sin Ketubá la pareja no puede convivir. La Ketubá simboliza el pacto que Moisés escribió antes de la revelación en el Sinaí. El pacto enumeraba las obligaciones mutuas entre Israel y Dios, así como la Ketubá enumera las obligaciones entre marido y mujer.

ROTURA DE COPA: En determinado momento de la boda judía se acostumbra romper cualquier cosa de vidrio, generalmente es una copa. Si bien la ceremonia nupcial es un momento de regocijo, la rotura de la copa, conmemora la destrucción del Beit Hamikdash, el Templo de Jerusalén, recordándonos que estamos aún en el exilio, que Jerusalén no está aún reconstruida. Otro significado, que muchos Rabinos refieren en la ceremonia, es que la copa, que, si bien no siempre se cumple, debe ser, por tradición, de cristal, representa la fragilidad del matrimonio. Con una simple pisada, puede quebrarse y, una vez rota, sería dificilísimo repararla, pegar sus partes. La pareja se asemeja en eso: la tradición recuerda a los novios que deben cuidar su matrimonio como si fuese una frágil copa de cristal. Existe otra explicación, más simple pero igual de poderosa, que es una expresión de deseo: "si algo se va a romper,

${ }^{16}$ El Ídish, o Yídish que significa literalmente judío. Es el idioma del judío proveniente de comunidades del centro de Europa comúnmente conocidos como ashkenazitas. La mayor parte de su sintaxis y léxico, les toma del alemán, con muchos giros del arameo y del hebreo.

${ }^{17}$ Cf. J. NeWMAN - G. SivÁN, Judaísmo de A-Z. Léxico ilustrado de términos y conceptos, Jerusalén 1983.

${ }^{18}$ Cf. J. CARO, Síntesis del Shulján Aruj, Buenos Aires 1968. 
que sea esta copa y no la pareja". Son diferentes las explicaciones dadas para la rotura de la copa $^{19}$.

Jal: Son dos letras hebreas que significan vida y misericordia. Es uno de los símbolos que tiene menos antigüedad, dentro de los más significativos del judaísmo. Se usa como colgante en cadenas y pulseras o como elemento de ornamentación. La palabra jai que está compuesto por las dos letras jet y yud, que son sus bases en la Tanakh y en el brith hadashah, y como se usa este símbolo de manera respetuosa y sin profanar las acertadas enseñanzas de los sabios de bendita memoria y las bellas enseñanzas de yeshua nuestro mesías al respecto ${ }^{20}$. Se refiere a Jesús de Nazaret

TORÁ: El Jumash o Pentateuco, son los cinco libros que Moisés escribió en el desierto tras recibir cada palabra directamente de Dios, y legó al pueblo de Israel para que guarden lo que hay allí escrito y de proceder así les vaya bien en este mundo y hereden la vida eterna. Lo componen cinco libros: Bereshit (Génesis), Shemot (Éxodo), Vaikrá (Levítico), Bamidbar (Números), Debarim (Deuteronomio). A su vez, cada uno de estos libros se subdivide en secciones más pequeñas, parashiot, que es el plural de parashá, o sea, sección semanal. Cuando el varón realiza el Bar Mitzvá es llamado por primera vez a leer la Torá.

COPA DE KIDUSH: La copa especial de Kidush (de kadosh, sagrado), usada en tantas ceremonias judías simboliza santidad, solemnidad, y la felicidad de la vida familiar. Es habitual regalar copas de Kidush para el nacimiento de un niño, un Bat Mitzvá, o una boda; muchas veces estas copas se convierten en preciados tesoros familiares pasados de generación en generación. La copa de casamiento, compartida por los novios bajo la jupá, simboliza su unión. Durante el Brit Milá (circuncisión), al concluir las ceremonias todos (incluso el niño) beben de la copa de vino, así como en el Bar Mitzvá el homenajeado canta la bendición del vino alzando esta copa. Es una tradición llenar las copas de Kidush hasta que desborde para simbolizar la gratitud $^{21}$.

\section{CEREMONIAL SOBRE EL NACIMIENTO}

\subsection{Vinculados con el nacimiento del varón judío hallamos dos rituales:}

a) Berit Mila (pacto de la circuncisión): Se cumple con el niño a los ocho días de nacido, tal como lo prescribe la Torá. "Dijo Dios a Abraham: “Guarda, pues, mi alianza, tú y tú

${ }^{19}$ Cf. http://www.fiestajudia.com/ceremonias/ceremonia-copa.shtml Visto 31-01-2016.

${ }^{20}$ Cf. http://lavozmesianicasefardita.blogspot.com.es/2011/07/el-jai-el-simbolo-de-la-vida.html Visto 31-01-2016.

${ }^{21} \mathrm{Cf}$. http://www.fiestajudia.com/consejos/simbolos-judios.shtml Visto 31-01-2016. 
posteridad: Todos vuestros varones serán circuncidados. Os circuncidaréis la carne del prepucio, y eso será la señal de la alianza entre yo y vosotros. A los ocho días será circuncidado entre vosotros todo varón, de generación en generación..."22. Cuando razones de salud del recién nacido lo impiden, la circuncisión puede postergarse hasta que el médico dé el visto bueno para realizarla. Mohel se llama el especialista que la ejecuta, tras pronunciar las bendiciones del caso, y sandak, la persona que es generalmente un pariente cercano del niño: su padre, abuelo, tío, el que sostiene al niño en sus brazos durante la operación, sentado en una silla especial que se denomina Kise shel Eliahu, "silla del profeta Elías". Después del Berit Mila o pacto de la palabra, se suele servir un agasajo a todos los presentes.

La circuncisión es el acto iniciático de la religión judía, tan importante en ella, que el Talmud sostiene que lo es, por sí sola, tanto como todos los demás mandamientos juntos ${ }^{23}$. Buena prueba de lo cual, el hecho de que, aunque el día de la circuncisión caiga en sábado o en Yom Kippur, en los que como se sabe, está prohibido para los judíos toda clase de trabajo, ésta ha de practicarse puntualmente en fecha tal. Mediante la circuncisión, la persona pasa a formar parte de la comunidad judía y recibe el nombre, de modo similar a como ocurre entre los cristianos con el bautismo. La circuncisión es, ante todo, el símbolo de la alianza entre Yahveh y el pueblo judío: "Dijo Dios a Abraham: [...] todos vuestros varones serán circuncidados. Os circuncidaréis la carne del prepucio y eso será la señal de la alianza entre Yo y vosotros. A los ocho días será circuncidado entre vosotros todo varón" 24.

Lo que no quiere decir que sólo el niño que nace judío haya de ser circuncidado. También cabe la circuncisión del adulto, necesaria en todo caso si a edad madura se pasa a engrosar las huestes de la religión judía: "Deben ser circuncidados el nacido en tu casa y el comprado con tu dinero"25. De la lectura del primer libro del Antiguo Testamento, el Génesis, cabe interpretar que el primer circuncidado fue Ismael, el hijo que Abraham tenía de su esclava Agar, aún no tenía a Isaac cuando estableció la alianza con Dios.

Después de él, circuncidó también "a todos los varones de la casa" y finalmente, a la edad de noventa y nueve años, se circuncidó él mismo ${ }^{26}$. Tenía Ismael, cuando fue circuncidado, trece años, edad que quedará marcada en la religión hebrea como aquélla en la

\footnotetext{
${ }^{22}$ Gn. $17,10-14$.

${ }^{23}$ Cf. P. Díaz-MAS - C. De LA Puente, Judaísmo e islam, Barcelona 2007, pp. 150-153.

${ }^{24}$ Gn. 17, 9-12.

${ }^{25}$ Gn. 17,13

${ }^{26}$ Cf. Gn 17, 23-27.
} 
que todo judío que no haya sido hecho circuncidar por su padre, está obligado a tomar la decisión de hacerlo por sí mismo.

La sanción del incircunciso, llamada karet, la prevé también el Génesis: "El varón a quien no se le circuncide la carne de su prepucio, ese tal será borrado de entre los suyos por haber violado mi alianza"27. En cuanto a las personas que no tienen prepucio al acceder al judaísmo, sea porque siendo neonatos nacen sin él (niños apostéticos), sea porque se trate de conversos que ya están operados, se realiza una ligera incisión en el pene tendente a producir una gota de sangre, sustitutiva de la circuncisión ritual.

$Y$ es que, a efectos de judaidad, no basta con carecer de prepucio para considerarse circuncidado, sino que dicha circuncisión ha de ser por encima de todo "ritual". A pesar de lo raro del caso (el de los niños apostéticos), el tema reviste importancia suficiente como para ser objeto de amplio debate en el gran libro judío de los debates, el Talmud, donde se puede leer al respecto. "El Rabbí Eleazar Hakappar dijo que las escuelas de Shamai y de Hillel no diferían por lo que respecta al niño nacido sin prepucio. Ambas están de acuerdo en que la sangre del pacto debe ser extraída del glande".

Y como buen ejemplo de lo extenuantes y exhaustivos que pueden llegar a ser los debates talmúdicos, valga como ejemplo el desenlace del versículo: "La escuela de Shamai sin embargo, acepta que tal operación puede ser realizada en sábado, en tanto que la otra entiende que el sábado no puede ser denigrado por tal razón"28.

En cuanto a la ceremonia, el niño es llevado al ceremonial por el kvatter y la kvatterin o nombre que recibe sólo entre los judíos askenazíes, suerte de padrinos de la ceremonia, habitualmente una pareja sin hijos que de esta manera hace méritos para tenerlos. La operación la lleva a cabo el llamado mohel, e implica tres fases: primero, la milah, o ablación de la parte superior del prepucio; segundo, la peri'ah o descarnadura del pene; y tercero la metsitsah, o succión bucal de la herida con intenciones higiénicas, hoy día en total desuso y sustituida por técnicas antisépticas mucho más apropiadas. La circuncisión ${ }^{29}$ del niño judío va acompañada de todo un acontecimiento de tipo festivo, el seudat mitzvah que tradicionalmente tenía lugar en la sinagoga, aunque hoy en día esto ocurra en rara ocasión

En al ámbito del judaísmo se ha constituido en debate tradicional el de la circuncisión de prosélitos, y aunque generalmente es incuestionable, no por ello dejan de existir grupos en los que se ha optado por la no exigencia de la misma, así la comunidad judía liberal de los

\footnotetext{
${ }^{27}$ Gn. 17, 14.

${ }^{28}$ Cf. http://archive.feedblitz.com Visto 31-01-2016.

${ }^{29}$ Cf. S. PH. De VRIES, Ritos y símbolos judíos, Madrid 2007², pp. 165-169.
} 
Estados Unidos. En cuanto al fundador del cristianismo, Jesús, como buen judío que era, fue efectivamente circuncidado, de lo que nos da buena cuenta el evangelista Lucas: "Cuando se cumplieron los ocho días para circuncidarle, se le dio el nombre de Jesús"30.

Y el tema sobre la circuncisión será el gran debate de la emancipación de la religión cristiana respecto de su tronco ancestral, la judía. Lo que no quita para que, el debate esté todavía sobre la mesa dado que, en algunas comunidades cristianas todavía hoy se practique aún la circuncisión ${ }^{31}$.

b) Pidion Haben: El "rescate del hijo" primogénito. Porque el primer hijo de la madre, cuando es varón debe ser consagrado a Dios ${ }^{32}$. Luego en el libro de los Números, la ley indica que "todo primogénito que se presente a Yahveh de cualquier especie, hombre o animal, será para ti (para los sacerdotes). Pero harás rescatar al primogénito del hombre... Los harás rescatar al mes de nacidos, valorándolos en cinco siclos de plata, en ciclos del santuario, que son de veinte óbolos"33.

Cuando se cumple un mes y un día de nacido, se realiza esta ceremonia en la cual el padre coloca al hijo delante de un cohen o sacerdote, para dar cumplimiento a dicha ley. $Y$ luego por una moneda de plata o una suma de dinero que varía según las diversas costumbres y países, lo rescata y obtiene de vuelta.

El Pidion Haben suele realizarse dentro del marco de una comida festiva, pero no en sábado o día de fiesta, por el aspecto del dinero que interviene en la ceremonia, en tal caso se lo posterga hasta el primer día hábil siguiente. Y quedan eximidos del "rescate" los hijos de los mismos sacerdotes o de los levitas.

\subsection{Bar Mitzva y Bat Mitzva}

Ceremonia que se realiza al cumplir los trece años los varones y doce las niñas. Literalmente significa "Hijo del Mandamiento o del precepto", pero la intención del término denota "sujeto al mandamiento", vale decir "obligado a cumplirlo". Desde este día, rigen para

\footnotetext{
${ }^{30}$ Lc. 2, 21.

${ }^{31}$ Cf. http://www.religionenlibertad.com/articulo.asp? Idarticul =23601 Visto 16-06-2013.

${ }^{32}$ Cf. Ex 13,2.

${ }^{33}$ Num.18, 15.
} 
el joven judío todos los deberes que la religión impone para los adultos: ha dejado de ser un niño que quedaba exento de ellos ${ }^{34}$.

Como expresión pública de lo primero está la obligación de colocarse tefilin ${ }^{35}$ o filacterias que, durante la plegaria matutina de los días hábiles, también suele ponerse el talit "manto ritual" aunque en algunas comunidades comienza a usarlo después de su casamiento y la manifestación de sus derechos consiste en que ya se lo cuenta como hombre adulto para el minian o el mínimo de diez varones necesario para la oración pública y puede ser llamado a la Torah los sábados y días de fiesta.

El tallet es un paño rectangular, generalmente de lana que va provisto de flecos o zizit en sus cuatro ángulos.

La segunda etapa tiene lugar el sábado siguiente: el joven es llamado por primera vez a la Torah, envuelto en su talit. Además de leer la Torá, también se acostumbra que el joven recite después la Haftara o capítulo de los profetas del sábado en cuestión.

Otro elemento que queda a cargo del joven es el discurso o derasha, que generalmente aprende de memoria: allí expone algún tema bíblico tomado del texto que acaba de leer, subraya la importancia para él y su familia, agradece a sus maestros, etc. Finalmente, se festeja junto con su familia, de acuerdo a las posibilidades de cada uno, ya sea en la misma sinagoga o en un lugar preparado para la ocasión. Se le entregan regalos.

En el caso de las niñas, la Bar Mitzva es una costumbre muy reciente en el pueblo judío, motivo por el cual no están totalmente establecidas las tradiciones. $Y$ debido a que las mujeres no participan en la conducción de un servicio sinagogal, no se ha desarrollado ninguna ceremonia tradicional para marcar el momento en que una niña se convierte en Bat Mitzvá. Muchas veces suele celebrarse en forma colectiva, juntas todas las niñas de la comunidad que cumplieron sus doce años ${ }^{36}$.

\section{CELEBRACIÓN DEL MATRIMONIO EN LA RELIGIÓN JUDÍA}

Las ceremonias matrimoniales judías consisten en dos partes:

\footnotetext{
${ }^{34}$ Cf. P. DíAZ-MAS - C. DE LA PUENTE, Judaísmo e islam, Barcelona 2007, p. 153.

${ }^{35}$ Cf. Equipo de Redacción PaL, Historia de las religiones, Bilbao 1980, pp. 228-229.

${ }^{36}$ Cf. Equipo de Redacción PAL, Historia de las religiones, Bilbao 1980, pp. 232-233.
} 
a) Desposorio o Santificación (Kidushín), durante el cual la novia es prometida al novio al colocarle el anillo en su dedo a la vez que le dice: "He aquí que tú eres santificada o prometida a mí, con este anillo, según la Ley de Moisés y de Israel". Con esta declaración, y con el consentimiento de la novia, ésta se transforma en su esposa. Esta parte exige la presencia de dos testigos idóneos ${ }^{37}$.

b) Matrimonio (Nisuín) es la consumación de la promesa ${ }^{38}$. Queda simbolizada por la novia y el novio parados bajo el palio (jupá), en tanto se recitan las Siete Bendiciones (Sheva Berajot). La recitación de estas bendiciones exige la presencia de un minyán. Las bendiciones apropiadas para estas dos partes de la ceremonia las pronuncia el oficiante frente a una copa de vino. La novia y el novio beben del vino.

Además, se firma y se lee en público un documento matrimonial, la ketuba o ketuva, donde constan las obligaciones que el hombre toma sobre sí como esposo, y la indemnización que deberá pagar a la mujer en el caso de que alguna vez quiera divorciarse de ella ${ }^{39}$. Firman dos testigos de la ceremonia. Es costumbre romper un vaso cuando finaliza la ceremonia matrimonial, para recordar así la destrucción del antiguo Templo de Jerusalén por los romanos en el año $70 \mathrm{~d}$. C. "Romper un vaso" y prácticas semejantes en otras ocasiones fueron ordenadas por la Mishná para recordar la destrucción ${ }^{40}$.

Apagado el sonido de la rotura del vaso, se levanta la asamblea con grandes expresiones de felicidad, dando rienda suelta a todos los cordiales deseos, tanto por parte de los padres como parte de los familiares y de todos los invitados. También en la sinagoga, la casa y el hogar de la comunidad resuenan sonoramente las voces de todos.

Y se centran en una determinada expresión, como si fuese una salva que se descarga sobre la pareja de novios, que significa mucha felicidad, aunque la traducción más exacta sería que sería que tengan mucha estrella o también mucha suerte. Esto ha supuesto cambios en las expresiones que unas veces ganan en fuerza para lo que se quiere expresar y otras la pierden con el correr del tiempo ${ }^{41}$. Posteriormente llega el festejo, con el banquete y el baile ${ }^{42}$.

\footnotetext{
${ }^{37}$ Cf. S. PH. De VRIES, Ritos y símbolos judíos, Madrid 2007², pp. 189-194.

${ }^{38}$ Cf. S. PH. DE VRIES, Ritos y símbolos judíos, Madrid 2007², pp. 194-206.

${ }^{39}$ Cf. S. PH. DE VRIES, Ritos y símbolos judíos, Madrid 2007², pp. 206-212.

${ }^{40}$ Cf. B. SoRJ, Judaísmo para todos, Río de Janeiro 2011, pp. 87-90.

${ }^{41}$ Cf. S. PH. De VRIES, Ritos y símbolos judíos, Madrid 2007², pp. 210-211.

${ }^{42}$ Cf. P. Díaz-MAS - C. de La Puente, Judaísmo e islam, Barcelona 2007, pp. 153-157.
} 
El oficiante de la ceremonia es el rabino, quien pronuncia la sheva bejarot, las siete bendiciones. El rabino debe llenar una copa de vino que los futuros esposos compartirán antes de que el marido ponga un anillo de oro en el dedo índice de la mano derecha de su esposa y declare al mismo tiempo: Tú me eres consagrada por este anillo conforme a la ley de Moisés y de Israel. Recíprocamente, la novia debe de colocar el anillo al novio, como símbolo de su unión. El intercambio de anillos simboliza la toma del matrimonio.

Tras el intercambio de anillos, se lleva a cabo la lectura de la ketubá, el certificado matrimonial que anuncia las obligaciones del esposo para con la mujer. Este documento, además de ser firmado por los contrayentes, debe ser suscrito por dos testigos, que no deben tener ningún tipo de relación sanguínea con los novios. Una vez firmado el documento, los esposos son cubiertos por un manto, bajo el que escuchan el resto de oraciones restantes y las siete bendiciones que les protegerán en su vida marital.

Tras esto, el novio rompe un vaso de cristal, donde previamente han bebido el vino, y que ahora se ha colocado bajo sus pies. Esta tradición evoca la destrucción del Templo de Jerusalén hace más de dos mil años. De esta manera quiere recordar a los novios que, a pesar de estar viviendo momentos felices, en el matrimonio también se pasa por momentos difíciles en los que no hay que perder la fe. Durante los siete días posteriores a la boda, las familias y amigos de los recién casados los invitan a comer, ocasiones siempre clausuradas por las siete bendiciones ${ }^{43}$. La documentación necesaria será la siguiente: la partida de nacimiento de ambos contrayentes; la ketubá de los padres o certificado de matrimonio religioso; el libro de familia de los padres y un certificado de soltería ${ }^{44}$.

Los elementos necesarios en el matrimonio judío:

- Es la celebración del amor de un hombre y de una mujer, la ocasión de recordar sus obligaciones recíprocas y las que tienen hacia el pueblo judío.

- Los cónyuges tienen que ser los dos judíos.

- Probarán su pertenencia religiosa proporcionándole al rabino la Ketuba o acta de matrimonio religioso de sus padres.

- A menos de que haya una conversión, está prohibido desposar a una persona no judía en la sinagoga.

- Es posible casarse en la sinagoga de su elección, con la condición de haber contactado con el rabino previamente.

- Es posible casarse cualquier día excepto el sábado (shabbat), los días festivos y durante el período del Omer.

- Los invitados que no sean de confesión judía tienen derecho a asistir a la ceremonia. Los hombres tendrán que llevar en la cabeza una kippa.

\footnotetext{
${ }^{43} \mathrm{Cf}$. http://www.enfemenino.com/moda/las-bodas-judias-s448776.html Visto 16-12-2015.

${ }^{44}$ Cf. P. Díaz-MAS - C. DE LA Puente, Judaísmo e islam, Barcelona 2007, pp. 157-158.
} 
El tiempo del Omer es un período de siete semanas que nos llevan desde la festividad de Pesaj, la celebración de la libertad en la cual salimos cada año de Mitzraim, las limitaciones de la esclavitud de Egipto, hacia la festividad de Shavuot, "Las Semanas", la celebración de la Entrega de la Torá, cuando recibimos año tras año la Torá que nos enseña nuestro derrotero en el mundo. Como tal, la cuenta del Omer constituye el pasaje de la libertad hacia nuestro propósito en la vida, del estado en que podemos hacer lo que queramos a un estado en que sabemos lo que queremos hacer, en el cual estamos conectados a nuestro verdadero destino ${ }^{45}$.

\section{ENTIERRO O KEVURA}

Previo al entierro, y como recuerdo de la costumbre de tiempos antiguos en que los deudos solían desgarrar sus ropas como expresión de dolor por el fallecimiento ocurrido se ejecuta hoy la Keria ("rotura"), un tajo que se da en la ropa exterior de los familiares más cercanos. Hasta la sepultura, debe dejarse que los enlutados dejen aflorar su aflicción y dolor, y no se deben ofrecer condolencias. En el recinto en el que se encuentra el cuerpo se deben encender dos velas que se mantendrán encendidas hasta la salida del ataúd ${ }^{46}$. Las personas deben leer Salmos dedicados al alma del fallecido, mencionar las virtudes y las buenas obras que realizó, y mantener un ambiente de circunspección y sobriedad. No se debe comer, fumar o mantener conversaciones sin importancia en la habitación en que se encuentra el fallecido. Exhibir al muerto se considera deshonroso y falto de respeto.

Por consiguiente, durante el velatorio el cuerpo permanece cubierto. En lo concerniente al envío de flores, éste es un procedimiento que no se acostumbra en el judaísmo. Las flores o coronas de flores que por ventura fuesen enviadas para honrar al fallecido, especialmente por personas no judías, deben ser aceptadas, pero no se las debe colocar sobre el cajón ni llevar al cementerio; deben ser colocadas en una sala próxima al lugar del velatorio. Asistir a un funeral y acompañar los restos mortales hasta el cementerio es una de los mayores preceptos de la religión judía. Acompañar al cortejo fúnebre (Levaiá) y llevar al muerto a su última morada es un deber tan sagrado que incluso permite, en algunos casos, interrumpir el cumplimiento de otros preceptos religiosos ${ }^{47}$.

\footnotetext{
${ }^{45}$ Cf. http://www.fcje.org/ Visto 16-12-2015.

${ }^{46}$ Cf. S. PH. De VRIES, Ritos y símbolos judíos, Madrid 2007², pp. 251-2157.

${ }^{47}$ Cf. P. Díaz-MAS - C. de La Puente, Judaísmo e islam, Barcelona 2007, pp. 158-159.
} 
Preparación del difunto para el entierro: Primero, se debe realizar la preparación ritual del cuerpo, conocida como Tahará (purificación). Esta consiste en lavar el cuerpo y luego verter sobre él un flujo de agua en símbolo de purificación.

El respeto por el difunto y por la dignidad humana exige que los restos descansen en un estado de profunda limpieza física. Después de la Tahará se viste al difunto con los Tajrijim, (mortajas blancas) y para un hombre, se coloca sobre los tajrijim el talit (manto de oraciones) que usó en vida. Las mortajas señalan la igualdad absoluta que existe entre todos los seres humanos en el momento de la muerte. De este modo, no se perciben diferencias entre ricos y pobres en el momento de despedirse de nuestro mundo ${ }^{48}$.

Luego es llevado hacia la tumba, acompañado por el séquito que integran sus familiares, amigos, etc. Una vez allí se lo sepulta. Y al pie de la tumba, vuelta a cerrar, el hijo o algún familiar cercano (varón) pronuncia el kadish ${ }^{49}$, o plegaria especial para esta ocasión. Antes de salir del cementerio, los avelim, (enlutados) deben recibir el primer consuelo, como símbolo del comienzo del período de shiva. Los dolientes se sientan en un banco bajo, mientras los asistentes pasan delante de ellos y pronuncian las palabras de consuelo tradicional: "Que Dios les de consuelo junto a los dolientes del Pueblo de Israel y no sepan más de dolor" ${ }^{50}$. A la salida del cementerio, en cualquier ocasión, debe procederse al lavado de manos ritual, (Netilat ladaim). Se llena un vaso o una jarra con agua y se la vierte primero sobre la mano derecha y después sobre la mano izquierda, tres veces sucesivamente hasta vaciar la jarra.

De este modo se aleja simbólicamente la impureza creada por el contacto con la muerte. Para la familia comienza la shiva, o semana de luto en la casa ${ }^{51}$. Al volver del cementerio, los familiares de luto se sacan los zapatos y se sientan en sillas bajas o en el piso. La primera comida de los deudos, debe ser proporcionada por sus vecinos o amigos y no debe componerse de alimentos que se encuentren en la casa de quien está de duelo ${ }^{52}$.

Los parientes y amigos acostumbran a preparar una comida liviana, para que quienes están de duelo coman algo a la vuelta del cementerio. De hecho, la preparación de esta Seudat Havrahá (comida) es una mitzvá importante y una obligación religiosa. Al cabo de treinta días vuelven a reunirse para la Azkara (recordación) o Sheloshim, junto a la tumba, sobre la cual ya

\footnotetext{
${ }^{48}$ Cf. S. PH. De VRIES, Ritos y símbolos judíos, Madrid 2007², pp. 257-259.

${ }^{49}$ Cf. S. PH. DE VRIES, Ritos y símbolos judíos, Madrid 2007², pp. 264-267.

${ }^{50}$ Cf. S. PH. DE VRIES, Ritos y símbolos judíos, Madrid 2007², pp. 268-270.

${ }^{51}$ Cf. S. PH. De VRIES, Ritos y símbolos judíos, Madrid 2007², pp. 273-276.

52 Cf. S. PH. De VRIES, Ritos y símbolos judíos, Madrid 2007², p. 272.
} 
se colocó una lápida fúnebre con el nombre del difunto. Luego continúa el duelo por once meses para los familiares, período en el cual se sigue recitando el Kadish ${ }^{53}$.

\subsection{Servicio fúnebre en el judaísmo}

Se puede entender por judaísmo como "aquel sentimiento, una experiencia emocional de identificación con un universo psicológico y cultural que huye a las definiciones, pero dentro del cual se incluyen todos aquellos que de una forma u otra se sienten identificados con él"54.

La actitud del judío frente a la muerte no es trágica, ya que se considera un proceso natural de la vida, sin importar que tan joven sea el fallecido. La muerte, así como la vida, tiene un significado y son parte del plan divino. Los judíos creen fervientemente en que los muertos serán resucitados y que aquellos que vivieron una vida haciendo el bien, serán recompensados. Se cree que el terminar con una vida humana es terminar con un mundo entero y; que el salvar una vida significa salvar un mundo entero también.

El Judaísmo permite a las personas quebrar cualquier mandamiento divino si de eso depende el salvar una vida humana, con excepción de los mandamientos contra el homicidio, idolatría, adulterio e incesto.

La vida es muy valorada por sobre todas las cosas, sin embargo, cuando la muerte es inminente y el paciente está sufriendo, la ley judía permite dejar de prolongarle la vida si es de manera artificial. En ciertas circunstancias, también se permite el "desconectar" a un paciente. Dejemos claro que la eutanasia está prohibida dentro de las leyes judías. La autopsia no está contemplada dentro de las leyes judías a menos que la ley del país así lo requiera, y deberá ser mínimamente intrusiva. Los judíos siempre son enterrados bajo tierra, no cremados. Todos los judíos fallecidos son tratados con dignidad e igualdad ${ }^{55}$.

¿Cómo se realiza el funeral judío?

\subsection{La preparación del cuerpo}

1. Apenas muere una persona judía se le deberá cerrar los ojos y su cuerpo será cubierto y puesto en el suelo rodeado de velas encendidas.

\footnotetext{
${ }^{53}$ Cf. S. PH. De VRIES, Ritos y símbolos judíos, Madrid 2007², pp. 276-279.

${ }^{54}$ B. SORJ, Judaísmo para todos, Río de Janeiro 2011, p. 3.

${ }^{55}$ Cf. P. DíAz-MAS - C. De LA Puente, Judaísmo e islam, Barcelona 2007, pp. 159-160.
} 
2. Por respeto, nunca se deberá dejar solo al cuerpo hasta el momento del entierro. Las personas que acompañan al cuerpo se les llaman Shomerim o "Guardianes". Estos guardianes no deberán ingerir alimentos, agua o ninguna otra acción en presencia del fallecido por considerarse una falta de respeto grave y una burla. Muchas comunidades están organizadas de manera que ya tienen asignados a los guardianes (chevra kaddisha o sociedad sagrada) para servir ante la muerte de alguien. Este servicio es voluntario y es considerado extremadamente meritorio. Pero, por otro lado, la familia o la comunidad pueden llamar a una casa de servicios fúnebres para solicitar el servicio de guardianía, si así lo desean.

3. El cuerpo del fallecido es lavado en señal de purificación (Tahara). Si el fallecido es hombre, entonces este baño deberá ser ejecutado sólo por hombres y si el fallecido es mujer, serán las mujeres quienes la bañarán. Nunca se le pondrá boca abajo al fallecido. Luego se procederá a vestir el cuerpo con una túnica tradicional de lino color blanco llamada Takhrikhin.

4. Luego que el cuerpo está listo, se lo pondrá dentro de un cajón o ataúd de madera llamado Aron. El cuerpo debe ser enterrado lo antes posible, preferentemente antes de las 24 horas. No se entierra el cuerpo con joyas o ningún otro objeto, ya que el fallecido será juzgado por sus acciones y méritos y no por su riqueza material. El cuerpo del fallecido deberá estar completo, sin que ningún órgano haya sido removido.

5. El ataúd deberá tener varios orificios alrededor para no interrumpir el proceso natural de volver a la tierra. El cuerpo nunca debe ser mostrado durante el sepelio por considerarse una falta de respeto ${ }^{56}$.

\subsection{Costumbres y tradiciones}

En los funerales judíos más tradicionales no se usan flores por considerarse un adorno frívolo e innecesario, pero algunas otras familias pueden usar flores durante el servicio fúnebre con previa autorización del Rabino, y sólo si éste lo considera apropiado. Cuando un pariente cercano ya sea padre, hijo, esposo o hermano recibe la noticia del fallecimiento es tradición judía el arrancarse parte de la vestimenta sobre la zona del corazón (si el fallecido es el padre) o sobre el lado derecho del pecho (si es otro miembro cercano de la familia). Este ritual es conocido como K'riah. Mucha gente actualmente suele usar una cinta negra como símbolo de duelo. Cuando se ve a una persona usando la cinta negra se le deberá ofrecer las condolencias respectivas, aunque no se conozca al fallecido. La cinta o la ropa desgarrada deberá usarse por siete días, pero si el fallecido es el padre o madre entonces se deberá usar

\footnotetext{
${ }^{56}$ Cf. http://www.thebellmeade.com/costumbres-funerarias-judias-y-aceites-de-uncion/ Visto 31-01-
} 2016. 
por treinta días. El momento entre la muerte y el entierro del fallecido se le conoce como Anninut. En ese período de tiempo se permite que la familia cercana exprese todo su dolor. No se reciben visitas o llamadas para dar las condolencias durante el Anninut. El servicio fúnebre suele ser muy simple y normalmente dura unos 20 minutos aproximadamente. Luego del entierro es costumbre que la familia tenga que lavarse las manos. Después del entierro, un amigo cercano prepara la primera comida sólo para los dolientes cercanos. Esta cena es una importante tradición judía que simboliza la continuidad de la vida. Después de esta cena se podrán recibir las condolencias del caso. En cuanto a la música en los funerales judíos, la religión judía tradicional no permite el uso de melodía alguna durante el ritual fúnebre. Asimismo, se espera que la familia no asista a celebraciones donde se toque música por los próximos 12 meses, ya que la música se relaciona directamente con la alegría. Sin embargo, en los últimos años muchas familias judías vienen integrando la música como parte del servicio funerario a fin de homenajear al fallecido ya sea con su música favorita o con alguna melodía emotiva que la familia considere adecuada para honrar la memoria del difunto. Este acto deberá ser consultado con anticipación con el Rabino encargado de la ceremonia. Aquí compartimos con ustedes una hermosa melodía que podría ser usada en un servicio funeral judío ${ }^{57}$.

\subsection{Períodos del duelo judío}

\subsubsection{Período de Shiva}

Luego del entierro y la primera cena de la familia empieza el primer período de duelo llamado Shiva. El día del entierro es contado como primer día de Shiva y continúa por siete días. En caso que el Shiva coincida con alguna festividad judía, será el Rabino quien estará en posición de aconsejar a la familia doliente qué hacer en cada situación particular. La familia doliente se queda en casa durante el período de Shiva y es la comunidad judía la que visita a la familia para brindar su apoyo y consuelo. La familia sólo podrá salir de casa el día sábado (Shabbat) para ir a la Sinagoga. Durante este período se realizan tres servicios (mañana, tarde y noche) para recitar la oración de Kaddish y así reconfortar a la familia ${ }^{58}$. El ambiente de la casa debe ser de sumo respeto. Los visitantes no deben esperar ser atendidos como visitas, sino por el contrario, deberán entrar en silencio y podrán llevar comida o frutas para la familia doliente. Las conversaciones deben ser sobre el fallecido. La presencia de familiares, amigos y miembros de la comunidad es muy importante para la familia doliente ya que simboliza su aprecio y consideración. Durante el Shiva se dejará encendida una vela por un período de siete días.

\footnotetext{
${ }^{57}$ Cf. https://www.cjmadrid.org/identidad-judia/ciclo-de-vida/fallecimiento Visto 31-01-2016.

${ }^{58}$ Cf. P. Díaz-MAS - C. DE LA Puente, Judaísmo e islam, Barcelona 2007, p. 160.
} 


\subsubsection{Período Shloshim}

Este es el período de treinta días (Shloshim significa Treinta en hebreo) donde la familia del fallecido se reincorpora a sus trabajos, escuela, etc. Durante este período no se escucha música, cortarse el pelo, afeitarse, maquillarse y ningún otro tipo de forma de celebración. Si alguna celebración familiar interfiere con este período, se debe buscar al Rabino para absolver las dudas que puedan surgir.

\subsubsection{Período de Avelut}

Este es el período observado por los hijos del fallecido, y dura doce meses contados desde el día del entierro. Las fiestas, conciertos, teatros, etc. deben ser evitados. El hijo (s) del difunto deberá recitar la oración del Kaddish todos los días. Después de estos doce meses de duelo, la familia no estará permitida de continuar con el duelo formal, aunque algunas familias acostumbran recordar el año de fallecimiento en la Sinagoga (Yahrzeit). Todos los dolientes prenden velas en honor al fallecido las cuales permanecen encendidas por 24 horas ${ }^{59}$.

\subsection{Ceremonia de presentación de la Lápida}

Las leyes judías exigen la preparación de una lápida o Matzava a fin de que el fallecido no sea olvidado o profanado. La familia es libre de elegir el estilo de la lápida. Muchos optan por escribir el nombre del fallecido en hebreo. Es costumbre de algunas comunidades el dejar la lápida cubierta o instalarla después de terminado el período de duelo de doce meses Después del período de duelo, la lápida podrá ser descubierta. También es costumbre en algunas comunidades judías el dejar pequeñas piedras cuando se visita la tumba ${ }^{60}$. Es descubrimiento de la misma se hace en medio de una gran ceremonia. Se suelen recitar pasajes de la Mishná, y se recitan algunos salmos. La familia directa, representada por los hijos, reza el Kaddish, cuando la colocación de la misma se hiciera durante el curso del año de luto, o en el aniversario. La lápida ha permanecido durante ese tiempo tapada, se procede a su descubrimiento en ese momento y así poder leer su inscripción en hebreo. Desde ese momento la lápida permanecerá siempre en dicho lugar. Por eso la costumbre de los cementerios judíos de mantenerse íntegros, esperando el final de los tiempos ${ }^{61}$. Todas las lápidas poseen formas diversas, no son todas iguales, habiendo diversos tipos: unas planas, otras con forma de columnas, etc. No suelen faltar en las sepulturas las lápidas, y cuando están no se encuentran es porque antiguamente solían ser de madera como sucedía en los tiempos

\footnotetext{
${ }^{59} \mathrm{Cf}$. http://www.rememori.com/pagina/rituales-judios-ante-el-fallecimiento Visto 31-01-2016.

${ }^{60}$ Cf. http://www.redfuneraria.com/funeral-judio Visto 24-01-2016.

${ }^{61}$ Cf. Dan 12,13.
} 
más remotos ${ }^{62}$. En muchas ciudades y pueblos de Oriente, donde existieron centros judíos, se conservan los antiguos cementerios, que son por sí mismos la representación y la descripción de una secular e inveterada costumbre de marcado sentido judío. Ahí tenemos en famoso antiguo cementerio judío de Praga, en medio de la ciudad de Praga, en el distrito de Josefor, donde se encuentran las antiguas sinagogas del gueto.

\section{CONCEPCIÓN ESPIRITUAL DEL JUDAÍSMO}

El judaísmo afirma que Dios creó al hombre a su imagen y semejanza ${ }^{63}$, de ahí que la igualdad ante la ley quedaba ordenada dentro la religión y tradición judía. Se ha expresado con autoridad que la noción judía de que Dios ha creado a todos los hombres, en función de su imagen, manifiesta el concepto básico en el judaísmo que todos los hombres son iguales ante $\operatorname{Dios}^{64}$. Se destruye la imagen divina cuando se ha desposeído al hombre de su dimensión transcendente. Las consecuencias inmediatas de este precepto divino es la obligación y la necesidad de amar al prójimo como a uno mismo ${ }^{65}$ y la noción inmediata que se deriva de ella que es la fraternidad humana, proclamada insistentemente por el profeta Malaquías cuando se pregunta algunas cuestiones: ¿Acaso no tenemos un mismo Padre común todos nosotros? ¿Acaso no nos ha creado un mismo Dios? ¿Por qué obramos insidiosamente los unos contra los otros, profanando la Alianza? El tema de la Alianza es fundamental en la historia del pueblo de Israel ${ }^{66}$. Uno de los aspectos que involucra el concepto de fraternidad y de igualdad debe ser contrastada en función de sus implicaciones en la vida real. La piedra de toque esencial será la actitud frente al extranjero, al distinto, al otro. La Sagrada Escritura mantiene así al extranjero en un pie de igualdad con el judío. Una sola ley y una sola norma tendréis vosotros y el extranjero que mora con vosotros ${ }^{67}$. Será especialmente el profeta Ezequiel quien más ahondará en es te tema: Os repartiréis este país según las tribus de Israel; y echaréis suertes sobre él para poseerlo como heredad entre vosotros y los extranjeros residentes en medio de vosotros que hayan engendrado hijos en medio vuestro, pues serán para vosotros como nacidos entre israelitas, con vosotros echarán suertes para poseerlo como propiedad en medio de las tribus de Israel. En cualquier tribu en que el extranjero more, alli le darán su heredad,

\footnotetext{
${ }^{62}$ Cf. S. PH. De VRIES, Ritos y símbolos judíos, Madrid 2007², pp. 280-281.

${ }^{63}$ Cf. Gn. 1,27.

${ }^{64}$ Cf. A. SAMUEL, Para comprender las religiones en nuestro tiempo, Estella (Navarra) 2011, pp. 87-89.

${ }^{65}$ Cf. Lv 19,18.

${ }^{66}$ Cf. Mal. 2,10.

${ }^{67}$ Cf. Nm. 15,15-16.
} 
oráculo del Señor ${ }^{68}$. Por eso debemos tener en cuenta que el respeto por la igualdad humana entraña, por naturaleza, el respeto por la plenitud de los derechos involucrados en la forma en que cada ser humano se autodefine y el lugar que él se asigna en la familia humana. Ser humano, comunidad, pueblo, nación, religión se entrelazan. Es imposible abstraer al hombre de los contextos sociales a los que pertenece ${ }^{69}$.

El concepto judío de espiritualidad y, por tanto, de santidad (Qedusah) tiene su origen en la visión de que la religión no puede considerarse una especie de compartimiento estanco de la vida, sino más bien debe penetrar toda la existencia humana. Para el contexto del mundo judío, la adoración a Dios y la espiritualización de la existencia del hombre, vinculado al pueblo elegido ${ }^{70}$ significa fundamentalmente tender hacia la consecución de la santidad personal, manifestándola en todas y cada una de las acciones propiamente humanas. Por eso es tan determinante el concepto moral que se despliega a partir de los preceptos judíos. Así, Dios es santo, como expresión de la más alta y absoluta perfección moral. Si Dios es santo en sentido absoluto, exige que el pueblo de Israel, su pueblo, el pueblo escogido como "Reino de sacerdotes y nación santa"71, de aquí que su tradición y aplicación de la santidad sea para todos y en todos los momentos de su existencia tanto personal como familiar, social, cultural, económica y nacional ${ }^{72}$.

\subsection{El calendario judío}

La cultura cristiana, heredera directa de la cultura judía, mantiene en común con ella una fiesta, la Pascua, y su peculiar situación variable en el calendario ${ }^{73}$. El año judío es solar como el cristiano, pero los meses son lunares: de ahí que cada dos años o tres tenga que añadirse un mes bisiesto para adecuar el cómputo de los meses lunares al año solar, por ello cada año la Pascua, y la Semana Santa que la precede, caen en fechas distintas. El calendario judío es eminentemente religioso ${ }^{74}$. Tiene instituida la semana, cuyos días se nombran por

\footnotetext{
${ }^{68}$ Ez 47, 21-23.

${ }^{69}$ Cf. http://www.radiojai.com.ar Visto 30-01-2016.

${ }^{70}$ Cf. P. Díaz-MAS - C. DE LA Puente, Judaísmo e islam, Barcelona 2007, pp. 72-78.

${ }^{71}$ Ex 19,6 .

${ }^{72}$ Cf. A. Mạ. TAPIA - ADLER, Introducción al judaísmo, Santiago de Chile 2010.

${ }^{73}$ Cf. P. DíAz-MAS - C. DE LA PUENTE, Judaísmo e islam, Barcelona 2007, pp.68-71.

${ }^{74}$ C. Pereda Roig, Concordancia de los Calendarios de la Hégira y de la Era Cristiana, desde el año 1 de aquélla hasta el 2000 de ésta, Tetuán 1941.
} 
ordinales y empezando por el domingo, para ajustarse a los días de la creación del mundo. Los seis primeros días son laborables, y el séptimo, que sí tiene nombre, el "Shabbath" (Reposo), es el día de descanso, como en el relato bíblico ${ }^{75}$.

En la actualidad se sigue la siguiente denominación de los meses:

Primer mes: Tisrí (septiembre/octubre).

Segundo mes: Hesván (octubre/noviembre).

Tercer mes: Kislev (noviembre/diciembre).

Cuarto mes: Tebet (diciembre/enero).

Quinto mes: Shebat (enero/febrero).

Sexto mes: Adar (febrero/marzo).

Séptimo mes: Nisán (marzo/abril)

Octavo mes: lyar (abril/mayo).

Noveno mes: Siván (mayo/junio).

Décimo mes: Tamuz (junio/julio).

Undécimo mes: Ab (julio/agosto).

Duodécimo mes: Elul (agosto/septiembre).

Para nuestro estudio podemos afirmar que "el calendario hebreo, lunisolar, solar el año y lunar el mes, se basa, por tanto, en el ciclo de la Tierra alrededor del Sol y de la Luna alrededor de la Tierra. Comienza con la Creación, o génesis, del mundo que, según la religión judía, tuvo lugar en la noche entre el domingo y el lunes 7 de octubre del año 3761 d.C. Esta cifra, que se obtiene sumando las edades de las distintas generaciones mencionadas en la Biblia, sería en data hebrea el 1 tishri del año 1. La semana judía consta de siete días, pero comienza en domingo, que los sefardíes llaman alhad, y acaba en el sabat, que es el día consagrado a Dios. Sin embargo, hay que tener en cuenta, como ya se ha indicado, que el nuevo día comienza para los judíos no con el amanecer, sino con la puesta de sol del día anterior; así el sabat no comienza al amanecer del sábado, sino en el anochecer del día anterior, viernes. Para una conversión de fechas aproximada, se debe sumar o restar la cifra

\footnotetext{
${ }^{75}$ Cf. A. C. AVRIL - D. De LA Maisonneuve, Las fiestas judías, Estella (Navarra) 2001, pp. 7-11.
} 
3761 pero, debido a que tiene desigual duración el año cristiano y el hebreo, para obtener la datación exacta habrá que acudir a las tablas cronológicas"76. El año 2018 corresponde al año 5778 del año judío.

\subsection{Las fiestas judías}

Celebran los grandes momentos de la historia de la salvación en sus fiestas anuales ${ }^{77}$. De esta manera se encuentran la Pessah o liberación de Egipto; la Chavuoth o fiesta de las semanas en las que se conmemoran la renovación de la alianza del Sinaí y la recepción de la ley; la Rosch Ha Chana o primer día del año y aniversario de la creación, que es tiempo de penitencia por los pecados del pasado año y Yom Kippur o fiesta de las expiaciones ${ }^{78}$. "Escucha, (shemá) Israel: el Señor, nuestro Dios, es el único Señor. Amarás al Señor, tu Dios, con todo tu corazón, con toda tu alma y con todas tus fuerzas. Las palabras que hoy te digo quedarán en tu memoria, se las inculcarás a tus hijos, y hablarás de ellas cuando estando en casa y yendo de viaje, acostado y levantado; las atarás a tu mano como un signo, serán en tu frente una señal; las escribirás en las jambas de tu casa y en tus portales"79. La plegaría judía sirve igualmente para cualquier cristiano que puede apreciar los dones de Dios Uno sino también de Dios Trino y que hace posible el sentido de su amor y misericordia para su pueblo (Israel) y el nuevo pueblo de Dios (Iglesia). Esta es la Alianza de Dios con su Pueblo, prefigurada en el AT y realizada en el $\mathrm{NT}^{80}$.

1. Tisrí (septiembre/octubre): "Rosh ha-Shanah" (Comienzo del año judío).

2. Tisrí (septiembre/octubre): "Yom Kippur" (El Día del Perdón).

3. Tisrí (septiembre/octubre): "Sucot" (Recuerda la salida de la esclavitud en Egipto).

${ }^{76}$ Cf. F. Martín Escudero, “Calendario judío e islámico, ¿Dataciones exóticas en la península?”, en J. C. Galende - J. De SAntiago FernÁndeZ, X Jornadas de Documentación. El calendario y la datación histórica, Madrid 2011, pp. 221-247: especialmente 234-236.

77 Cf. C. Del Valle, La Misná, Salamanca $2011^{2}$. Es fundamental para el estudio del judaísmo y su protocolo.

${ }^{78}$ Cf. D. De LA MaIsonneuve, Le judaïsme, París 1984, pp. 36 ss.

${ }^{79}$ Dt 6, 4-9.

${ }^{80}$ Cf. D. GIRA, Las Religiones, Bilbao 1994, p. 45. 
4. Tisrí (septiembre/octubre): "Simjat Tora" (Este día se termina la lectura de la Torá).

5. Tebet (diciembre/enero): "Jannukká" (Recuerda la victoria de los Macabeos sobre los griegos).

6. Shebat (enero/febrero): "To Bisvat" (Se juntan para plantar árboles y merendar dulces y frutas).

7. Adar (febrero/marzo): "Purim" (Celebra la historia del Antiguo Testamento).

8. Nisán (marzo/abril): La Pascua "Pesaj" (conmemorando la salida del pueblo de Egipto, en una cena en la cual se junta toda la familia).

9. Iyar (abril/mayo): "Lag Baomer" (Se hacen hogueras y arcos con flechas en memoria de la resistencia judía).

10. Tamuz (junio/julio): "Bicurim" o "Savohot" (La Fiesta de la recogida del Campo y recepción de la Torá).

11. Ab (julio/agosto): ayuno Tisha (Conmemora la destrucción del primer templo de Jerusalén) ${ }^{81}$.

\section{LA SINAGOGA}

La palabra sinagoga viene del vocablo griego synagogé, que originalmente significaba reunión. Con el tiempo tomó el sentido de asamblea local de judíos, y posteriormente pasó a designar el edificio en que se reunían las congregaciones judías. Si bien se desconoce la fecha exacta en que se comenzaron a usar sinagogas como lugares de reunión, se suele aceptar que la práctica nació después de la destrucción del primer templo, cuando una gran parte del pueblo judío fue llevada a Babilonia ${ }^{82}$.

El exilio podría haber conducido a una integración total del pueblo judío en la cultura babilónica, que era más amplia; así que las reuniones para orar y estudiar no solo mantuvieron a los exiliados judíos apegados a su fe, sino que también los ayudaron a conservar su identidad nacional y cultural aun viviendo en el extranjero ${ }^{83}$.

\footnotetext{
${ }^{81}$ Cf. S. PH. DE VRIES, Ritos y símbolos judíos, Madrid 2007², pp. 299-303.

${ }^{82}$ Cf. P. DíAz-MAS - C. DE LA Puente, Judaísmo e islam, Barcelona 2007, pp. 99-110.

${ }^{83}$ Cf. A. SAmuel, Para comprender las religiones en nuestro tiempo, Estella (Navarra) 2011, p. 100.
} 
En cada sinagoga había un grupo de ancianos de la localidad que dirigía las actividades. También estaba el jefe de la sinagoga, cuya función era mantener a la congregación fiel a la Torá. Es probable que el jefe de la sinagoga se escogiera de entre el grupo de ancianos.

En la sinagoga había también otros cargos, como el de limosnero, que era la persona encargada de recoger y distribuir limosnas entre los necesitados, y el de jazán o asistente, que cuidaba los rollos de las Escrituras y anunciaba el inicio y el final del sábado soplando un cuerno de carnero en cuanto aparecían las tres primeras estrellas en el cielo vespertino. El culto del sábado comenzaba con la asamblea recitando el shemá: Escucha, Israel: el Señor, nuestro Dios, es el único Dios ${ }^{84}$.

Luego venía una lectura de fragmentos de los rollos de la Torá o los cinco primeros libros de las Escritura judía y de los Nevi'im o profetas. La persona que leía se ponía en pie y leía unidades de uno a tres versículos en hebreo, que seguidamente se parafraseaban en arameo, puesto que no todos los judíos del siglo I entendían el hebreo. Dentro de la sinagoga, por lo general había bancos a lo largo de tres de las paredes, reservados para las autoridades. Es posible que el resto de la congregación se sentara en esteras o tapetes. Era costumbre que la persona que enseñaba o instruía permaneciera siempre sentada:

a) Elementos de la sinagoga para el culto

En las sinagogas el principal objeto ceremonial es el Arca Sagrada, que puede tener la forma de un simple armario de madera, o de uno ornamentado. El Arca por lo general está en alto, su acceso se hace a través de una escalera y está decorada con ilustraciones magníficas de los Diez Mandamientos o tabla de la Ley. El Arca se sitúa normalmente adosada o empotrada en la pared que mira hacia Jerusalén. Posee una cortina bordada y gran profusión en su decoración, por lo general de un grueso terciopelo y en otras ocasiones son puertas de madera decoradas. Una sinagoga suele tener varios juegos de cortinas para el Arca: lisas para los días de semana, decoradas para Shabat y fiestas, blancas para las grandes festividades.

El objeto ceremonial más importante es el rollo de la Torá, el Pentateuco, que relata la historia del pueblo judío y difunde los mensajes universales del monoteísmo y del comportamiento ético. Se lo guarda constantemente en el Arca, salvo para la lectura pública. El rollo, formado de grandes trozos de pergamino cosidos juntos, puede llegar a una altura de hasta $80 \mathrm{~cm}$. Está montado en dos varas de madera para enrollarlo, levantarlo y portarlo. En la costumbre ashkenazí o centroeuropea, las manillas de estas varas están cubiertas generalmente por coronas o remates de algún metal fino. La Torá está atada con una faja, lisa o bordada, que se desata solamente cuando se lee en público, y está protegida por una funda,

\footnotetext{
${ }^{84}$ Cf. Dt 6,$4 ; 11,13-21$ y Num $15,37-41$
} 
por lo general bordada. Un pectoral, recuerdo del que usaba el Sumo Sacerdote, cuelga desde las manillas sobre la funda. En las comunidades sefardíes el rollo de la Torá es colocado en una caja cilíndrica, barnizada y decorada, y por lo general envuelta con una faja. La mayoría de las cajas son de madera, pero existen también modelos en plata y en oro.

El rollo de la Torá es tratado con la máxima reverencia, aunque, por supuesto, no es adorado. Al igual que los tefilín ${ }^{85}$, no debe ser dejado caer, ni debe ser llevado a un lugar impuro. El pergamino del rollo de la Torá no se toca excepto cuando es absolutamente necesario. El lector se ayuda de un puntero de madera o de plata que tiene en su extremo una mano con el índice extendido.

Las sinagogas pueden tener rollos adicionales; los más comunes son El Cantar de los Cantares, Rut, Eclesiastés y Ester, que se leen públicamente en Pésaj, Shavuot (Pentecostés), Sucot y Purim, respectivamente. Algunas sinagogas tienen un arca separada con los rollos de los libros bíblicos de los que se leen las haftarot, las lecturas públicas suplementarias en Shabat y fiestas.

El rollo que más comúnmente se encuentra, después de la Torá es el de Ester, que cuenta el relato de Purim. Dado que no menciona el nombre de Dios, es de menor santidad que los demás rollos y se encuentra en muchos hogares. Se lo mantiene en una caja hecha de madera, plata u otros materiales. Una lámpara ornamental, símbolo de la luz eterna en el Templo de Jerusalén, se coloca frente al Arca. Las sinagogas pueden funcionar perfectamente sin esta lámpara, y muchas sinagogas en Israel carecen de ella.

Los objetos ceremoniales en la sinagoga incluyen un shofar (Shofarot), un cuerno de carnero que se hace sonar al término de los servicios matutinos durante el mes anterior a Año Nuevo (Rosh Hashaná), en Rosh Hashaná mismo y en el Día del Perdón (Yom Kipur). Los shofarot por lo general no son ornamentados, pero pueden estar grabados siempre que la boquilla permanezca intacta. Las paredes de la sinagoga están adornadas con diversos objetos. Uno de ellos es el Shiviti: A Dios he puesto [en hebreo Shiviti] siempre delante de $\mathrm{mi}^{86}$. Otros objetos son noticias de la sinagoga y una señal indicando la dirección de Jerusalén. Muchas sinagogas cuentan con un sillón alto muy labrado y ornamentado que permanece vacío durante la ceremonia de la circuncisión, que se realiza a los varones de ocho días de

${ }^{85}$ Consiste de dos pequeñas cajas de cuero unidas a correas de cuero. Cada una de las dos cajas contiene cuatro secciones de la Torá escritas en pergamino. Esos pasajes son: Shemá (Deut 6,4-9), que proclama la Unicidad de Dios; Vehaia (Deut 11:13-21), que expresa la promesa de Dios de que nos recompensará si seguimos observando los preceptos de la Torá; Kadesh (Éx 13,1-10), el deber del pueblo judío de recordar siempre la redención de la servidumbre egipcia. Vehaia (Éx 13,11-16), la obligación de todo judío de informar de esto a sus hijos.

${ }^{86}$ Sal 16,8 . 
edad. Este mueble es conocido con el nombre de la Silla de Elías ${ }^{87}$, donde el profeta Elías es llamado el ángel del pacto [en hebreo brit], que también quiere decir circuncisión ${ }^{88}$.

b) El Shabat o sábado

Shabat es una voz hebrea que significa "descanso". Comienza el viernes a la caída del sol y concluye al anochecer del sábado ${ }^{89}$. Durante ese tiempo, todo el trabajo habitual se detiene. Este día los judíos han de abstenerse de ejecutar cualquier trabajo, tal como sembrar, arar, hornear, coser, encender o extinguir fuego y generar cualquier tipo de electricidad. El sábado se destina al estudio y a la instrucción religiosa, con el fin de satisfacer las necesidades espirituales.

Por esta razón, el shabat es un acto profundo que representa la liberación de las preocupaciones rutinarias, la tranquilidad, la alegría y la elevación espiritual ${ }^{90}$. Los ritos familiares comprenden tres acciones: encender las dos velas acompañadas de una oración realizada por la madre en el inicio de Shabat; al final del mismo otra oración recitada por el padre denominada habdala o separación; y el tercer elemento, que es el culmen la recitación de qiddus, realizada sobre la copa de vino antes de la comida familiar. Es el rito más antiguo. Consiste en bendecir y compartir una copa de vino y más tarde un trozo de pan, después de la cena del sábado ${ }^{91}$. Este es uno de los aspectos más importantes de la religiosidad judía y que a su alrededor gira todas las vivencias de la comunidad judía.

Los orígenes del sábado están en el libro del Génesis: El séptimo día concluyó Dios la obra que hizo, y reposó el séptimo día de todo cuanto había hecho. Entonces bendijo Dios el séptimo día y lo santificó, porque en él reposó de toda la obra que había hecho en la creación ${ }^{92}$. Aparte de ser un día para descansar, siguiendo el ejemplo de Dios, también evoca redención, como se explica en Deuteronomio: Acuérdate de que fuiste siervo en tierra de Egipto, y que el

${ }^{87} \mathrm{Mal} 3,1$.

88 Cf. http://www.mfa.gov.il/mfa/mfaes/facts\%20about\%20israel/pages/objetos\%20ceremoniales Visto 31-01-2016.

${ }^{89}$ Cf. A. SAMUEL, Para comprender las religiones en nuestro tiempo, Estella (Navarra) 2011, pp. 104-105.

${ }^{90}$ Cf. P. Díaz-MAS - C. DE LA PuEnTE, Judaísmo e islam, Barcelona 2007, pp. 126-129.

${ }^{91}$ Cf. A. Rodríguez Carmona, La religión judía. Historia y teología, Madrid 2001, pp. 664-667.

${ }^{92}$ Cf. Gn 2, 2-3. 
Señor, tu Dios, te sacó de allá con mano fuerte y brazo extendido, por lo cual el Señor, tu Dios, te ha mandado que guardes el sábado ${ }^{93}$.

El sábado semanal es un recordatorio de la misericordia de Dios al conceder a Su pueblo redención y reposo de la esclavitud que sufrió en Egipto. Es un recordatorio semanal del amor y la misericordia divina. La intención era que fuera una bendición, no una carga. Jesús aceptaba que el sábado era un día reservado por Su Padre para descansar y rendirle culto. Sin embargo, se oponía a las tradiciones e interpretaciones que no cuadraban con el propósito del sábado. No hacía caso de las nimiedades, de las tradiciones, que ponían el sábado por encima de las personas para las que este debía ser una bendición.

Como bien dijo: El sábado fue hecho por causa del hombre, y no el hombre por causa del sábado ${ }^{94}$. De acuerdo con el verdadero sentido del sábado, un día para hacer memoria de la bondad de Dios, un día de bendición, de descanso, para recordar la misericordia, liberación y redención divina, Jesús curaba los sábados. Para Él era un día en que estaba bien realizar actos de misericordia, aunque eso le causó conflictos con los fariseos, que consideraban que las sanaciones constituían un trabajo y por lo tanto contravenían las reglas sobre el sábado.

\section{c) Pésaj}

La pascua judía o Pésaj comienza durante el mes de Nisán (abril-mayo) y coincide con el inicio de la primavera. En estas fechas se celebra el aniversario de la liberación judía de la esclavitud en Egipto ${ }^{95}$. Es una fiesta pastoril en la que se acostumbraba a sacrificar un cordero y se lo compartía bien en la familia o con el clan. Originariamente celebraba el fin del invierno y el comienzo de la primavera ${ }^{96}$. Cuando Moisés sale con el pueblo de Israel, de la esclavitud de Egipto, se convierte en una fiesta nacional, adoptando su nombre que significa "paso" 97 .

El mundo judío la celebra con la luna llena del mes de nisán, días 14-15, dando así comienzo el año cultural judío. De acuerdo con esta regla, no existe necesariamente coincidencia entre Pascua y el día semanal del culto, que en el judaísmo es el sábado o sabbath, por lo que puede caer en cualquier día de la semana. Los festejos duran siete días y durante este tiempo no se pueden ingerir alimentos derivados de cereales fermentados. En su lugar se come pan sin levadura. La fiesta posee carácter de memorial de la liberación y

\footnotetext{
${ }^{93}$ Dt 5,15.

${ }^{94}$ Mc 2,27.

${ }^{95}$ Cf. F. G. Voltaggio, Las fiestas judías y el Mesías, Madrid 2018, pp. 113-139

${ }^{96}$ Cf. P. Díaz-MAS - C. DE LA Puente, Judaísmo e islam, Barcelona 2007, pp. 133-139.

${ }^{97}$ Cf. A. C. AvriL - D. de LA Maisonneuve, Las fiestas judías, Estella (Navarra) 2001, pp. 19-36.
} 
también de medio para aprenderla, valorarla y defenderla ${ }^{98}$. Es el eje de toda la vida espiritual y religiosa de los judíos, pues sin ella no tendría sentido la Alianza de Dios con su pueblo, el de Israel.

d) Shabuot o Fiesta de las semanas o de las Primicias

En la fiesta se Shabuot o Pentecostés que se celebra durante los meses de mayo y junio, siete semanas después del segundo día de Pascua, período llamado Sefirat Ha'omer se recuerda y conmemora la entrega de los Diez Mandamientos o Torah $^{99}$ al pie del Monte Sinaí, por Dios a Moisés ${ }^{100}$. Así como el agradecimiento por la producción agrícola, pues es la época en que las tierras del Norte, en especial Israel, se recogen los primeros frutos, las primicias y que antiguamente servían durante la peregrinación como ofrenda para el templo ${ }^{101}$. También es conocida como fiesta de la conclusión, "aseret". Así se terminaba el ciclo de ofrendas de primicias y de otra, porque desde el punto de vista histórico termina el ciclo de la Pascua cuya culminación es el don de la Torah ${ }^{102}$.

e) Tishá Be Av

Es uno de los días tristes del calendario, debido a que permanecen en la memoria la destrucción de los dos Templos de Jerusalén ${ }^{103}$.

\section{f) Rosh ha Shaná}

Tishei (septiembre-octubre) es el mes en el que inicia el nuevo año judío y se indica el comienzo de la creación divina. En ese periodo se festeja Rosh ha Shaná ${ }^{104}$, o año Nuevo judío y es un momento dedicado a la reflexión ${ }^{105}$. Comienzo de "año espiritual judío". Se celebra el primero y segundo día Tishrei, mes en que se dice: "Dios creó el mundo". Ocurre el día siguiente a la luna nueva que se produce próxima al equinoccio de septiembre y se hace sonar

\footnotetext{
${ }^{98}$ Cf. A. Rodríguez Carmona, La religión judía. Historia y teología, Madrid 2001, pp. 667-672 y 682-683.

${ }^{99}$ Cf. F. G. Voltaggio, Las fiestas judías y el Mesías, Madrid 2018, pp. 141-159.

${ }^{100}$ Cf. A. C. AVRIL - D. De La Maisonneuve, Las fiestas judías, Estella (Navarra) 2001, pp. 37-48.

${ }^{101}$ Cf. P. DíAZ-MAS - C. DE LA PUENTE, Judaísmo e islam, Barcelona 2007, p. 139.

102 Cf. A. Rodríguez CARMona, La religión judía. Historia y teología, Madrid 2001, pp. 683-684.

${ }^{103}$ Cf. A. C. AvriL - D. DE LA Maisonneuve, Las fiestas judías, Estella (Navarra) 2001, pp. 116-119.

${ }^{104}$ Cf. F. G. Voltaggio, Las fiestas judías y el Mesías, Madrid 2018, pp. 15-36.

105 Cf. M. GuerRa GómeZ, Historia de las religiones, Madrid 2010, pp. 324-326.
} 
el "shofar", un cuerno de carnero, llamando al pueblo a la reflexión, meditación y arrepentimiento durante un período de diez días que recibe el nombre de Yamim Noraim o días temibles y que termina en el Yom Kippur ${ }^{106}$. Es una de las fiestas austeras con las del Yom Kippur. Quedan determinadas por la conciencia y confesión de los pecados para volver a la alianza ${ }^{107}$. Por tanto, en primer lugar, se recuerda la creación hecha por parte de Dios y el hombre goce con su colaboración; en segundo lugar, los hechos salvíficos con lo que Dios comienza a reinar, creando un mundo adecuado para sus hijos; en tercer lugar, es el día del recuerdo o memorial, para que Dios se acuerde del hombre ${ }^{108}$.

\section{g) Yom Kippur}

Yom Kipur se celebra el 9 -10 del mes Tishei (septiembre-octubre); es una de las fechas más sagradas del calendario judío, ya que celebra el Día del Perdón, de la penitencia y de la purificación espiritual ${ }^{109}$. Es día de ayuno y abstinencia que se considera el más solemne y santo del año. Se trata de un perdón expiatorio ${ }^{110}$. Es obra de Dios, un don con el que Dios renueva su promesa de creación y alianza, sin tener en cuenta la infidelidad del pueblo. El perdón de Dios está condicionado por el perdón del hermano. Yom Kippur reconcilia con Dios si en los días previos penitenciales uno se reconcilia con el hermano.

El perdón es la fuerza creadora de Dios que no se resigna al fracaso de la historia humana. En este sentido ha hecho de este día la fiesta más observada de manera universal por el judaísmo ${ }^{111}$. El libro del Levítico describe minuciosamente el ceremonial a seguir: el Sumo Sacerdote ofrecerá un cabrito en sacrificio al Señor y enviará otro, cargado con todas las culpas del pueblo, a morir al desierto112. Después, el Sumo Sacerdote entrará en el "Santo de los Santos", una única vez durante todo el año, y pronunciará por tres veces el nombre de Yahvé, una también única vez durante todo el año, invocando su perdón y bendición para todo el pueblo ${ }^{113}$.

\footnotetext{
${ }^{106}$ Cf. A. C. AVRIL-D. De LA Maisonneuve, Las fiestas judías, Estella (Navarra) 2001, pp. 71-88.

${ }^{107}$ Cf. P. DíAz-MAS - C. DE LA PUENTE, Judaísmo e islam, Barcelona 2007, pp. 130-131.

108 Cf. A. Rodríguez Carmona, La religión judía. Historia y teología, Madrid 2001, pp. 683-684.

${ }^{109}$ Cf. F. G. Voltaggio, Las fiestas judías y el Mesías, Madrid 2018, pp. 39-56.

${ }^{110}$ Cf. A. C. AvriL - D. DE LA Maisonneuve, Las fiestas judías, Estella (Navarra) 2001, pp. 95-107.

${ }^{111}$ Cf. A. Rodríguez Carmona, La religión judía. Historia y teología, Madrid 2001, pp. 689-691.

${ }^{112}$ Cf. Lev. 16, 1-34.

113 Cf. P. Díaz-MAS - C. DE LA Puente, Judaísmo e islam, Barcelona 2007, pp. 131-133.
} 
h) Sukkot o Sucot o Tabernáculos o Tiendas y Simjat Torá

La recolección de los frutos en el desierto se evoca también en el mes Tishrei, en la fiesta de los tabernáculos o Sucot o Sukkot ${ }^{114}$, durante siete días entre el 15 y 22 de dicho mes $^{115}$. También rememora el deambular del pueblo por el desierto del Sinaí y la necesidad de morar precariamente en tiendas o cabañas provisionales o sucá. Antiguamente al igual que en Pascua y en Shavuot, se acostumbraba a peregrinar hacia el Templo de Jerusalén ${ }^{116}$.

Ocho días después, se completa el ciclo anual de la lectura del Torá; este festejo es llamado Simjat Torah y significa "alegría" o "regocijo de la Torah" ambas fechas también son celebradas con alegría reverente ${ }^{117}$. Es la idea que expresa el himno, que se canta al comienzo de la liturgia sinagogal de esta fiesta, en el que además se pide a Dios, que habita con su Sekiná en medio del pueblo, lo ilumine y los proteja ${ }^{118}$.

i) Hannukká o las Luminarias

En el mes de Kislev (noviembre-diciembre), Janucá o Jannukká ${ }^{119}$ conmemora la emancipación de los judíos frente al rey Antíoco que intentaba destruir su religión y forzarlos a adoptar la fe griega ${ }^{120}$. Es la fiesta de las Luminarias, como recordando la derrota helénica a manos de los patriotas Macabeos y la posterior retirada de todos los símbolos paganos del Templo de Jerusalén ${ }^{121}$. No figura ni en Torah, ni la Biblia protestante.

Esto se debe a que el Libro de los Macabeos se considera "deuterocanónico", pero si fue aceptado en la Biblia católica. Según la tradición, durante el acto de purificación del Templo, la menorah, o candelabro de los siete brazos, ardió ocho días con una exigua caridad de aceite que sólo alcanzaba para un día, todo un milagro. Por eso la fiesta abarca ocho días

\footnotetext{
${ }^{114}$ Cf. F. G. Voltaggio, Las fiestas judías y el Mesías, Madrid 2018, pp. 63-86.

${ }^{115}$ Cf. A. C. AvriL - D. DE LA Maisonneuve, Las fiestas judías, Estella (Navarra) 2001, pp. 47-64.

${ }^{116}$ Cf. P. DíAz-MAS - C. DE LA PUente, Judaísmo e islam, Barcelona 2007, pp. 140-141.

117 Cf. P. DíAz-MAS - C. DE LA Puente, Judaísmo e islam, Barcelona 2007, pp. 141-142.

${ }^{118}$ Cf. A. Rodríguez Carmona, La religión judía. Historia y teología, Madrid 2001, pp. 686-688.

${ }^{119}$ Cf. F. G. Voltaggio, Las fiestas judías y el Mesías, Madrid 2018, pp. 87-102.

${ }^{120}$ Cf. P. DíAz-MAS - C. DE LA PUENTE, Judaísmo e islam, Barcelona 2007, pp. 142-143.

${ }^{121}$ Cf. A. C. AvriL - D. DE LA Maisonneuve, Las fiestas judías, Estella (Navarra) 2001, pp. 109-111
} 
( 25 de kislev al 3 de tevet, en que se enciende una vela por noche en un candelabro de 9 velas llamado "janukía", antes del primer día se enciende la vela central ${ }^{122}$.

\section{j) Purim o Salvación y Lag Baomer}

Esta fecha se celebra durante la luna llena del mes de Adar (febrero-marzo), en los días 14-15 y es una fiesta de regocijo y gozo en al que se expresa alegría por el rescate de los judíos en Persia, cuando salvaron sus vidas de manos de Amán, consejero del rey Asuero o Jerjes I, quien se disponía a exterminarlos ${ }^{123}$. Se conmemora el milagro mencionado en el libro de Esther ${ }^{124}$. Es obligatorio primero ayunar y orar como lo hicieron aquellos judíos; luego vendrá el banquete y se beberá abundante vino... hasta que ya no se pueda pronunciar bien el nombre de Amán. Por eso, esta fiesta se asemeja en muchos aspectos a los que otros pueblos celebran en estas mismas fechas que se llaman carnavales, donde puede existir cierto desenfreno y regocijo generalizado ${ }^{125}$.

En el último mes, lyar (marzo-abril), Lag Baomer se relaciona con el inicio de la primavera y la Pésaj ${ }^{126}$. En resumen, las fiestas religiosas se clasifican en tres grandes grupos o apartados: las fiestas de la peregrinación más importantes son Pésaj - Pascua; ShaboutPentecostés, y Sucot - Tabernáculos; las fiestas austeras Rosh Hazaña y Yom Kipur y, por último, están las fiestas menores. La diferencia entre ellas radica en el contenido de la celebración ${ }^{127}$. Todas dan curso al funcionamiento del año judío. Todas ellas son conmemoraciones para recordar ciertos acontecimientos pasados de la historia de pueblo elegido, el pueblo judío ${ }^{128}$.

\section{INDUMENTARIA RELIGIOSA EN EL MUNDO JUDÍO}

Hay atuendos propios de ritos religiosos como es el caso de la kipa. La kipa, es una pequeña gorra ritual empleada por los varones judíos para asistir a la sinagoga u otros lugares

\footnotetext{
${ }^{122}$ Cf. A. Rodríguez CARMona, La religión judía. Historia y teología, Madrid 2001, pp. 692-693.

${ }^{123}$ Cf. A. C. AvriL - D. DE LA Maisonneuve, Las fiestas judías, Estella (Navarra) 2001, pp. 114-115.

${ }^{124}$ Cf. F. G. Voltaggio, Las fiestas judías y el Mesías, Madrid 2018, pp. 103-111.

${ }^{125}$ Cf. P. DíAz-MAS - C. DE LA Puente, Judaísmo e islam, Barcelona 2007, pp. 143-145.

${ }^{126}$ Cf. A. Rodríguez Carmona, La religión judía. Historia y teología, Madrid 2001, pp. 693-694.

${ }^{127}$ Cf. J. M. MARTíneZ, “Fiestas judías”, en Tierra Santa 2 (№ 21: Enero-Febrero 2014) 6-9.

${ }^{128}$ Cf. A. SAmuel, Para comprender las religiones en nuestro tiempo, Estella (Navarra) 2011, pp. 103-104.
} 
sagrados, o incluso si recitan alguna plegaria en su propio domicilio deben de llevarla puesta. Actualmente también está aceptada por los no ortodoxos, en las mujeres. La costumbre proviene del Talmud, tradición oral hebrea que marca leyendas, costumbres y leyes.

Dios está por encima de todo, por lo que como señal de respeto se deben cubrir la cabeza ante él. Pero debe quedar claro que el uso de la kipa es una tradición, no una ley divina. Este pequeño casquete identifica al judío en todo el mundo. La kipa está hecha de tela, cuero o de lana tejida muy apretada. Hay numerosas variaciones de color y diseño, incluso se hacen con el escudo del equipo de futbol o dibujos de héroes infantiles, aunque se sigue llevando blanco en las bodas y negro en señal de luto. Los judíos observantes la llevan durante todo el día. La kipa es usada tanto por adultos como por niños y aunque es de uso opcional, cada vez lo usan más entre la población israelí, que se muestra orgullosa de su identidad. Los católicos tienen muchos ritos heredados del judaísmo, así los grandes estamentos eclesiásticos también se cubren en presencia de Dios con un casquete similar a la kipa, pero que denominan solideo. En los obispos es color violeta, los cardenales color rojo y el papa color blanco, que simbolizan la protección de Dios y la dedicación sólo a Dios.

Los judíos usan el talit, chal que se emplea durante la oración. Generalmente es de lana blanca, tiene flecos o borlas en sus cuatros esquinas y se coloca de modo que cubra la espalda y caiga hacia adelante sobre los hombros. A veces también puede cubrirse la cabeza con él. Todo varón judío debe vestir su talit durante la oración común. La herencia del talit es el humeral o paño de hombros que se utiliza en la exposición y bendición del sacramento o con el traslado de reliquias como las del Lignum crucis. Suele presentar el talit unos flecos que reciben el nombre de tzitzit que son una representación física de los 613 harás y no harás presentes en el Torá. El talit no suele tener un color específico que lo represente, pero el negro es una opción clásica debido a que simboliza el exilio y destrucción que tuvo Jerusalén.

La costumbre de llevar kipá no proviene de un precepto o mandamiento propiamente dicho, a diferencia del talit o chal ritual, o de los tefilín o filacterias, aunque se ha arraigado con el correr de los siglos, al punto de convertirse en uno de los atributos más emblemáticos del judaísmo. Aun así, sus orígenes son igualmente milenarios, y se remontan al Talmud, simbolizando la necesidad de tener presente en todo momento que Dios está por encima de los hombres y las cosas; y solo pretende que la cabeza no quede descubierta ante Dios, pues nunca se puede estar descubierto en su presencia ${ }^{129}$.

\section{TRATAMIENTOS EN LA RELIGIÓN JUDÍA}

${ }^{129} \mathrm{Cf}$. http://diccionario.sensagent.com/kipa/es-es/ Visto 31-01-2016. 
A la hora de relacionarnos con una persona, ya sea presentándola, hablando con ella o escribiéndole una carta, es fundamental conocer el tratamiento que debemos utilizar al dirigirnos a ella. Siempre deberemos utilizar el tratamiento más adecuado. Los tratamientos suelen venir definidos por razones de cargo que se ostenta o por razones de méritos contraídos. Normalmente los tratamientos por razones de cargo suelen ser limitados en el tiempo, mientras que los determinados por razones de méritos o título suelen ser permanente y vitalicios, es decir se mantienen en el tiempo mientras lo haga la persona que ostenta el mérito o título. La utilización de los tratamientos adecuados, es un símbolo de respeto hacia la persona a la cual nos dirigimos. El tratamiento más generalizado es el tratamiento de Señor Don / Sra. Dña., que utilizamos para dirigirnos a la mayoría de las personas. Siempre debemos utilizar el Señor con el apellido y el Don con el nombre de pila, o utilizar la fórmula completa Señor Don con el nombre completo de la persona a la cual nos estamos dirigiendo. Cuando concurran circunstancias en determinadas personas, que tengan más de un cargo o mérito, siempre se debe utilizar el tratamiento de más alto rango que le corresponda. En caso de duda en la utilización de un tratamiento, lo mejor es consultar, o poner el inmediato superior. Es mejor tratar a una persona con un grado superior que inferior. En el caso de la religión judía, los términos para dirigirnos a sus representantes más importantes son rabino y Gran rabino. Los rabinos son los que se encuentran encargados de las sinagogas ${ }^{130}$. Además, en Jerusalén existen dos rabinos de especial consideración denominados Gran Rabino. Éstos son el sefardí y el ashkenazí.

Por otra parte el Gran rabino Sefardí de Jerusalén y Primado de Sión. El otro es el Gran rabino ashkenazi de Jerusalén. El gran rabino ashkenazi y el gran rabino sefardí son los dos encargados de los aspectos administrativos legales en la siempre delicada relación entre el Estado de Israel y los representantes del Gran Rabinato religioso. A nivel de conocimientos e interpretaciones de la Torá, no son las máximas autoridades. Ambos son las autoridades principales religiosas del judaísmo. El rabino ashkenazi representa las comunidades hebreas procedentes de Europa central y oriental; el sefardí, es heredero de las tradiciones de Europa meridional, especialmente de España, de donde fueron expulsados en 1492. Ambos son elegidos cada cinco años por el Parlamento judío llamado Knéset. No tienen ninguna función sagrada, sino ritual e institucional. Junto a ellos, existe el hebraísmo ultra ortodoxo, opositores del ideal sionista.

\section{BALANCE}

Podemos definir sionismo como aquel movimiento político encaminado a la reunión de los judíos en una nación. Esta definición permite diferenciar con claridad los términos de

\footnotetext{
${ }^{130}$ Cf. B. SoRs, Judaísmo para todos, Río de Janeiro 2011, pp. 82-86.
} 
judío y de sionista, conceptos que la propaganda sionista ha querido confundir pero que cualquiera con el más mínimo sentido común podrá distinguirlos. De un lado, se trata del judío que pertenece al pueblo que habitó la actual Palestina en tiempos ya pretéritos y de otro, también se denomina judío a quien profesa la fe de Moisés. Cuando hablamos de judíos nos estamos refiriendo a aquellos individuos que se sienten pertenecientes a una tradición cultural común, esta definición engloba a las dos acepciones usuales del término judío ${ }^{131}$. El judaísmo es esencialmente un proyecto político. Para los judíos es muy determinante trabajar por un mundo y una sociedad en paz, una paz destinada a ser plenamente universal y permanente. Por lo tanto, no es una coincidencia que la palabra paz o shalom en hebreo, sea hallada frecuentemente en cualquier discurso judío a todos los niveles. El judaísmo es mucho más que una religión, sin embargo, muchos judíos se consideran judíos y ateos o agnósticos abiertos al mismo tiempo a un mundo mucho más real, y dicen que ni pertenecen ni son auténticos judíos absurdamente, puesto que el judaísmo es una religión y no una raza.

Con seguridad Flavio Josefo ${ }^{132}$ es uno de los grandes historiadores judíos. Miembro del partido fariseo, descendía de una antigua familia hebrea. Nació Jerusalén en el año 37 y murió en Roma en el año 101 d.C. En la actualidad se trata de la única fuente para conocer los grandes rasgos de la historia judía, y resulta también muy útil para la historia romana. Escribió en lengua griega La guerra de los judíos, Antigüedades de los judíos y Contra Apión, éste último es tratado contra el antisemitismo grecorromano, tan extendido en su época, pues en Roma existían fuertes sentimientos contra Judea por causa de la guerra judeo-romana y él escribe en tiempos difíciles como fueron los de la posguerra. Esto nos puede descubrir la existencia de un antisemitismo latente en aquella sociedad que se ha venido arrastrando inveteradamente. Ese antisemitismo no es de hoy ni tampoco del siglo pasado ${ }^{133}$.

${ }^{131}$ Cf. J. B. Agus, La evolución del pensamiento judío, Buenos Aires 1979; L. BAECK, La Esencia del judaísmo, Buenos Aires 1964; J. L. BLAU, Las variedades modernas del judaísmo, Nueva York 1966; A. A. CoHEN, El Judío natural y lo sobrenatural, Londres 1967; E. L. FACKENHEIM, ¿Qué es el judaísmo?: una interpretación para nuestra época, Buenos Aires 2005; M. GIlbeRT, (ED.), El Atlas Ilustrado de la civilización judía, Buenos Aires $1988 ;$ D. Goldberg - J. RAYNeR, El pueblo judío, Londres 1987; J. Goldin, La expresión judía, Londres 1976; A. J. HeSCHEL, Dios en la búsqueda del Hombre, Nueva York 1955; J. NEUSNER, La vida de la Torá: Lecturas en la experiencia religiosa judía, Belmont (California) USA 1974; J. NEUSNER, El camino de la Torá, Belmont (California) USA 1988; J. NEUSNER, Un rabino habla con Jesús, Madrid 2008; D. J. PLATA - B. MARTIN, Una historia del judaísmo, 2 Vols. Nueva York 1974; Z. Sobel - B. BeIt - Hallahmi, (EdS.), Tradición, Innovación, Conflicto: el judaísmo en Israel Contemporáneo, Nueva York 1991; G. WigOdER, Enciclopedia del judaísmo, Nueva York 1989.

132 Cf. J. GonZÁlez-ECHegARAY, Flavio Josefo. Un historiador judío de la época de Jesús y de los primeros cristianos, Salamanca 2012, pp. 75-88.

${ }^{133}$ Cf. A. EBAn, Mi pueblo, la historia de los judios, Buenos Aires 1973; J. Álvarez, Judíos y cristianos ante la historia, Madrid 1972; J. BARYLKo, Introducción al judaísmo, Buenos Aires 1977; G. BAUM, Los judíos y el Evangelio, Madrid 1965; P. E. DION, Universalismo religioso de Israel, Estella (Pamplona) 1976; A. GonZÁLEZ LAMADRID, Los descubrimientos del Mar Muerto, Madrid 1973; E. Mitre FernÁNDEZ, Judaísmo y cristianismo: raíces de un gran conflicto histórico, Madrid 1980; J. L. REPETTO BETES, Ecumene. Análisis de la controversia judaizante, 
La historia ha desarrollado todo el protocolo que se sigue en los diversos actos y celebraciones de la comunidad judía. En su ceremonial religioso se han visto las principales prácticas litúrgicas y rituales que existen en las diferentes sensibilidades del judaísmo. A través de su protocolo religioso, se ha dado a conocer y entender el porqué de tales simbolismos, el ritmo en sus actos y la fuerza de sus ceremonias, como canales de expresión del fundamento y enseñanzas en las que creen profesan; sus usos, tradiciones, costumbres, disposiciones, ceremonias, celebraciones, que son la principal razón de su ser. Por eso es muy importante conocer la liturgia que se sigue; las celebraciones, fiestas más relevantes de la fe judía; los rituales utilizados para el culto, así como los acuerdos realizados por el Estado con la Federación de comunidades judías ${ }^{134}$.

\section{CONCLUSIÓN}

En un sentido cristiano, podemos destacar cómo la Sagrada Familia, se sometió a todas las prescripciones de la Ley judía, desde la circuncisión de Jesús ${ }^{135}$, la purificación de la madre y el rescate del primogénito ${ }^{136}$ sin tener necesidad de ello si miramos a quienes lo realizaron, Jesucristo y la Virgen María. Pero quizás Nuestro Señor vivir bajo la Ley "para rescatar a los que estaban bajo la Ley", y para perfeccionar la Antigua Ley, con la Nueva que apunta a la conversión del corazón. Por eso san Pablo escribe, con tanta vehemencia en su carta a los Romanos: "El verdadero judio lo es interiormente, y la verdadera circuncisión es la del corazón, la que se hace según el espíritu y no según la letra de la Ley. A este le corresponde la alabanza, no de los hombres, sino de Dios"137. Se está refiriendo a la dimensión interna del hombre donde mora el Señor, será en el interior del hombre, en su corazón donde está el auténtico judío, en el corazón circundado, mucho más esencial que la circuncisión física.

Finalmente, todos estos actos se llevaron a cabo en el Templo de Jerusalén, como preludio del mayor sacrificio del cordero Pascual cuando derramaría su Sangre y se ofrecería

Jerez de la Frontera (Cádiz) 1972; A. M. TeSTEMAlLE, ¿Silencio o ausencia de Dios? Ensayo sobre el problema de Dios en la obra de los pensadores judíos contemporáneos: Wiesel-Bloch-Neher, Madrid 1975; R. E. BROWN, El nacimiento del Mesías, Madrid 1982; R. E. Brown, La muerte del Mesías, T. I y T. II, Pamplona 2005 y $2006 ;$ A. Edersheim, La vida y los tiempos de Jesús el Mesías, Madrid 1989; J. GNiLKA, Jesús de Nazaret: Mensaje e historia, Barcelona 1993; J. JeREMíAS, Jerusalén en tiempos de Jesús, Madrid 2000; E. P. SANDERS, Jesús y el judaísmo, Madrid 2004; R. H. SteIN, Jesús el Mesías, Madrid 2008; N. T. WRIGHT, La resurrección del Hijo de Dios, Pamplona 2008.

${ }^{134}$ Ley 25/1992 de 10 de noviembre por la que se aprueba el Acuerdo de Cooperación del Estado con la Federación de Comunidades israelitas de España, en BOE (no 272/1992) de 12 de noviembre de 1992, pp. 3821138214.

\footnotetext{
${ }^{135}$ Cf. Lc. $2,21$.

${ }^{136}$ Cf. Lc. 2,22.

${ }^{137}$ Rom 2,29.
} 
sin defecto ni mancha como el primogénito, el Hijo de Dios en remisión de los pecados del mundo, como cuerpo entregado y sangre derramada ${ }^{138}$.

"Como es, por consiguiente, tan grande el patrimonio espiritual común a cristianos y judíos, este Sagrado Concilio quiere fomentar y recomendar el mutuo conocimiento y aprecio entre ellos, que se consigue sobre todo por medio de los estudios bíblicos y teológicos y con el diálogo fraterno.

Aunque las autoridades de los judíos con sus seguidores reclamaron la muerte de Cristo, sin embargo, lo que en su Pasión se hizo, no puede ser imputado ni indistintamente a todos los judíos que entonces vivían, ni a los judíos de hoy. $Y$, si bien la Iglesia es el nuevo Pueblo de Dios, no se ha de señalar a los judíos como reprobados de Dios ni malditos, como si esto se dedujera de las Sagradas Escrituras. Por consiguiente, procuren todos no enseñar nada que no esté conforme con la verdad evangélica y con el espíritu de Cristo, ni en la catequesis ni en la predicación de la Palabra de Dios. Además, la Iglesia, que reprueba cualquier persecución contra los hombres, consciente del patrimonio común con los judíos, e impulsada no por

138 Cf. S. AlcoBA, Los judíos, Barcelona 1973; S. BARÓN, Historia social y política del pueblo judío, 8 Vols., Buenos Aires 1968; E. BAROUKH - D. LEMBERG, Enciclopedia práctica del judaísmo, Barcelona 1995; A. BENVENISTE, Le Bosphore à la Roquette: La communauté judéo-espagnole à Paris (1914-1940), Paris 1989; H. H. BEN-SASSON, (ED.), Historia del pueblo judío, Madrid 1991; A. BERMAN, Nazism: The Jews and American Zionism 1933-1948, Detroit 1990; Ma. J. CANO - M. A. EsPINOSA, Historia y cultura del pueblo judío, Granada 2008; J. P. CAVERo ColL, El pueblo judío en la Historia, política, sociedad, religión y cultura, Madrid 2014; A. Chouraqui, Historia del judaísmo, Barcelona 1963; H. Crouzel, Origène, Paris 1985; A. D. Crown, "Redating the schism between the judaeans and the samaritans", en The Jewish Quarterly Rewiew LXXXII (July-October 1991) 17-50; N. R. M. DE LANGE, Judaísmo, Barcelona 1996, Madrid 2003 y 2006; H. DE LUBAC, Histoire et Esprit. L'intelligence de l'Existence d'après Origène, Paris 1950; G. Del Olmo LeTE, Origen y persistencia del judaísmo, Estella (Navarra) 2009; C. Del VAlLE, El mundo judío, Madrid 1978; I. EPSTEIN, Judaism. A Historical Presentation, Londres 1974; E. GALBIATI, Exilio, retorno y judaísmo, Madrid 1985; R. GoldenberG, The Origins of Judaism. From Canaan to the Rise of Islam, Cambridge 2007; T. HeRzL, El Estado Judío, Leipzig 1902, Wasghinton 1946, Barcelona 2005; L. JacoBS, God, Torah, Israel: Traditionalism without Fundamentalism, Cincinnati 1990; P. Johnson, La Historia de los judíos, Buenos Aires 1991; S. E. KARFF, “Una respuesta a fundamentalismo judío contemporáneo”, Concilium XXVIII (241:1992) 459-466; W. KELLER, Historia del pueblo judío, Barcelona 1969; J. H. LAENEN, La mística judía. Una introducción, Madrid 2006; N. DE LANGE, El judaísmo, Madrid 2000; J. MAIER, Das Judentum. Von der biblischen Zeit bis zur Moderne, Múnich 1973; J. MAIER - P. SCHÄFER, Diccionario de judaísmo, Estella (Navarra) 1996; K. MARX, La cuestión judía, Buenos Aires 2004; R. MATE - R. Forster, El judaísmo en Iberoamérica, Madrid 2007; M. MATZliah Melamed, El judaísmo, Madrid 1981; E. Mitre FernándeZ, Judaísmo y cristianismo, raíces de un gran conflicto histórico, Madrid 1980; J. NEUSNER, "El reto de fundamentalismo judío contemporáneo", en Concilium XXVIII (241:1992) 453-458; M. ORIAN, Maimónides: vida, pensamiento y obra, Barcelona 1984; X. PIKAZA - A. AYA, Diccionario de las tres religiones. Judaísmo, cristianismo, Islam, Estella (Navarra) 2009; A. Rodríguez CARMONA, La religión judía: Historia y teología, Madrid 2002; E. SCHOPEN, Historia del judaísmo en Oriente y Occidente, Alcoy (Alicante) 1970; H.-J. SIEBEN, Einleitung zu Origenes. In Lucam homiliae, Freiburg 1991; L. SUÁREZ FERNÁNDEZ, Los Judíos, Barcelona $2004 ;$ R. TOAFF, La Nazione Ebrea a Livorna e a Pisa (1591-1700). Storia dell'ebraismo in Italia, Florencia 1990; J. TOULAT, Los judíos, mis hermanos, Barcelona 1964; J. TRebolle BARRera, El judaísmo moderno, Madrid 2001; C. VIDAL ManzanARes, Textos para la historia del pueblo judio, Madrid 1995; J. Voderholzer, Henri de Lubac, TypologieAllegorese-Geistiger Sinn, Freiburg 1999. 
razones políticas, sino por la religiosa caridad evangélica, deplora los odios, persecuciones y manifestaciones de antisemitismo de cualquier tiempo y persona contra los judíos.

Por los demás, Cristo, como siempre lo ha profesado y profesa la Iglesia, abrazó voluntariamente y movido por inmensa caridad, su pasión y muerte, por los pecados de todos los hombres, para que todos consigan la salvación. Es, pues, deber de la Iglesia en su predicación el anunciar la cruz de Cristo como signo del amor universal de Dios y como fuente de toda gracia" 139 .

Ningún cristiano que desee vivir intensamente una relación auténtica con el conjunto de los demás fieles que pertenecen a otras confesiones y grandes religiones, de manera especial con las monoteístas o religiones del Libro, nunca podrán dejar en saco roto el día 27 de octubre de 1986. Era la primera ocasión, y no sería la única, que peregrinos llegados de todo el mundo, de las más variopintas tradiciones, se dieron cita en Asís, para orar por la Paz: judíos, musulmanes, sijs, budistas, animistas africanos, sintoístas, amerindios, jainistas, sintoístas, hinduistas, zoroástricos, bahaís, cristianos de todas las confesiones, ortodoxos, anglicanos, luteranos, calvinistas, evangélicos y católicos. Todos se sintieron protagonistas y a la vez llamados al corazón espiritual del mundo, para participar en la oración por la paz verdadera ${ }^{140}$.

A esto, ya había abierto y llamado el Concilio Vaticano II, mediante la Declaración Nostra Aetate ${ }^{141}$. Era impresionante ver todo el colorido de expresiones en cada uno de los peregrinos que se apostaban en el atrio de la Basílica para seguidamente situarse todos unidos, puestos en semicírculo para el encuentro de oración por la paz.

El protocolo se desarrolló en tres actos. En el primero el Santo Padre llegó a la Basílica de santa María de los Ángeles y en la puerta central de la Basílica fue recibiendo a todas las delegaciones, puesto que había sido una invitación suya para orar con todas por la paz. Ya en el interior de la misma, las distinguidas personalidades religiosas se colocaron en semicírculo en torno a la Porciúncula. Tras el canto del Salmo 148, al que siguió un tiempo de recogimiento en silencio, el Pontífice pronunció un discurso en el que explicó la finalidad del encuentro y el significado de esta singular Jornada.

A continuación, en el segundo, las delegaciones invitadas se distribuyeron por diversos lugares de Asís, donde cada una había elegido, y por separado, iba a hacer su oración por la

\footnotetext{
${ }^{139}$ Cf. Concilio Vaticano II, “Declaración Nostra Aetate”, 4, en AAS 58 (1966) 743.

${ }^{140}$ Cf. D. GIRA, Las Religiones, Bilbao 1994, pp. 7-8.

${ }^{141}$ Cf. Concilio Vaticano II, “Declaración Nostra Aetate”, 4, en AAS 58 (1966) 740-744.
} 
paz, para no interferir en las creencias de cada una. Era una jornada de ayuno, lo que contribuyó a la mayor dedicación al objetivo que era rezar por la paz.

En el tercero, todos grupos acudieron a la plaza de la basílica inferior de San Francisco, como peregrinos de la paz, en silencio, y allí se desarrolló la tercera parte de la Jornada, en la que, a partir de las 14,30 y por turno, cada una de las familias religiosas representadas oró en presencia de las demás, que asistían en silencio y respetuosamente. Sólo la familia a la que tocaba orar se destacaba un poco del grupo y recitaba su oración desde un atril que se hallaba colocado a un lado del escenario. El cardenal Roger Etchegaray hizo la introducción a la oración, hablando sobre la Jornada y sobre lo que significaba estar juntos para orar. Se fueron sucediendo la oración de los budistas, hindúes, jainistas, musulmanes, sintoístas, sijs, de las religiones africanas tradicionales, amerindia, zoroástricos, de los judíos y de los cristianos. En la celebración hubo cantos y gestos simbólicos, ramos de olivo, palomas blancas lanzadas al vuelo... Finalmente, el papa, Juan Pablo II pronunció el discurso final.

Aproximadamente hacia las seis de la tarde, los representantes de las diversas familias religiosas tuvieron con el santo Padre un ágape fraterno en el refectorio del convento de san Francisco y se dio por concluido el día de oración por la paz ${ }^{142}$. Todo el acto había sido cuidadosamente preparado por todas las delegaciones previamente al Encuentro de oración, en la que no apareció ni rastro de dificultad ni atisbo de complicación. El protocolo, llevado de la mano de la Santa Sede y de la diplomacia vaticana había sido un éxito rotundo.

Desde el punto de vista del protocolo se trataba de un gran desafío para poder alinear a todos sus representantes, a las grandes figuras y líderes espirituales de todo el mundo, que representaban a su vez los diversos credos religiosos existentes en ese momento en la sociedad mundial. Todos alrededor del patio de la Basílica se unieron en profunda oración.

Las grandes creencias, que han pervivido a lo largo de los siglos, siempre han creído que podían saber responder a las dificultades, imponderables y a las grandes preguntas del hombre ${ }^{143}$. Hoy la religión judía, con todo el acento que posee y tiene en sus liturgias, podemos decir en sus expresiones, manifestaciones y formas, hace atrayente a cualquier hombre, aunque no haya tenido contacto previamente con la dimensión religiosa, un cierto atractivo y en esto lago tiene que ver todo el protocolo que se sigue en sus celebraciones y ceremonias que se llevan a cabo tanto en el ámbito particular de la familia, es decir el privado, como en ámbito público que se realiza en la sinagoga, centro neurálgico de la sociedad judía. La sinagoga también es el vehículo para satisfacer las necesidades de la comunidad judía. El rabino inicia la lectura de la Shemá, pero tras la lectura de la Ley y los profetas, sigue una exhortación piadosa, que puede realizarla cualquier persona con la adecuada preparación,

\footnotetext{
${ }^{142} \mathrm{Cf}$. http://www.franciscanos.org/selfran45/jornadapaz86.html Visto 31-01-2016.

${ }^{143}$ Concilio Vaticano II, "Declaración Nostra Aetate”, en AAS 58 (1966) 740-744.
} 
que haya proclamado dichas lecturas. De esta manera, se difundió rápidamente el primer cristianismo, sobre la base de las predicaciones en las sinagogas de aquel tiempo. Ser expulsados de ella, suponía el destierro para dicha persona. El rabino tampoco es un presbítero o sacerdote como ocurre en la Iglesia católica y ortodoxa. Por eso no se sigue la analogía entre ambos conceptos porque son totalmente diversos y sin presupuesto común previo. Para ser rabino existe un consejo de rabinos que examina a los candidatos. Después se encuentra los Gran rabinos de Jerusalén: sefardí y ashkenazi de Israel. Se eligen por diez años.

La vida judía podría entenderse como la santificación del tiempo. Será, sin duda, en el reino del tiempo donde el hombre puede encontrar a Dios y tomar conciencia en cada momento como un acto creador de Dios ya que el tiempo es renovación continua y llevadera en el mismo tiempo. Un mundo en el tiempo es un mundo centrado en Dios. Es la realización del designio de Dios que es infinito, nunca una cosa en sí, sino una cosa hacia Dios y para Dios. El pensamiento histórico ha pertenecido a las maneras más elementales del modo judío de entender la existencia. Pero nada es definitivo en la historia, pero el pueblo judío está implicado en la misma historia como nosotros somos parte de ella. Sin duda, la historia de Israel, como pueblo de Dios ha hecho que la Sagrada Escritura no sólo haya recreado los hechos acontecidos en aquellos tiempos antiguos, sino que ha servido para orientar el presente tanto cultural como religioso, tanto de Oriente como Occidente, que es presente, se encuentra vivo y es actual. Si eso es así para el mismo cristianismo, también lo es con más razón para el judaísmo.

La liturgia pose un lugar privilegiado en la religión judía. Todo el conjunto de ritos, por perfectos que parezcan, no puedan sustituir a los deberes del corazón, la religión judía desarrollando a lo largo de su historia una serie de liturgias, perfiladas en sus más íntimos detalles. Consiguió la unidad de expresión con las ideas fundamentales del monoteísmo religioso que es la esencia de la religión de Israel.

Todas las acciones litúrgicas se integran dentro del conjunto de los preceptos de Dios, que tiene por finalidad llegar a la meta en su ascensión y perfección personal, social y comunitaria, individual e íntima. Toda acción litúrgica judía encierra en sí misma, la inmensa riqueza y la inestimable diversidad de la fe de la que se nutre. El libro de oraciones o Siddur tefiláh, es decir los rituales, que usan hoy en día los judíos está escrito en lengua hebrea y es el resultado de las grandes aportaciones sucesivas que han hecho de generación tras generación. Los textos de la liturgia de la sinagoga son todos de inspiración bíblica y manifiestan el amor y la fidelidad de Israel hacia la Sagrada Escritura. Todo esto queda reflejado en el ámbito del protocolo que siguen los rabinos en cada acción litúrgica en la sinagoga ${ }^{144}$. El protocolo sale muy beneficiado en el sentido litúrgico y ceremonial del

144 Cf. A. Ravenna, El hebraísmo postbíblico, Barcelona 1960, pp. 34 ss.; A. PenNA, La religión de Israel, Barcelona 1961; P. DemAn, Los judíos, fe y destino, Andorra 1962, especialmente cap. V; A. HERTZBERG, Judaísmo, 
judaísmo, porque expresa con mucha fuerza el sentido de sus creencias en Dios. Una religión, a ultranza monoteísta que tuvo sus grandes dificultades al estar rodeada por pueblos politeístas.

\section{BIBLIOGRAFÍA}

AlCOBA, S., Los judíos, Barcelona 1973.

ÁlVAREZ, J., Judíos y cristianos ante la historia, Madrid 1972.

AVRIL, A.C. - De La Maisonneuve, D., Las fiestas judías, Estella (Navarra) 2001.

AlcoBA, S., Los judíos, Barcelona 1973.

BARón, S., Historia social y política del pueblo judío, 8 Vols., Buenos Aires 1968.

BAROUKH, E. - LEMBERG, D., Enciclopedia práctica del judaísmo, Barcelona 1995.

BARYLKO, J., Introducción al judaísmo, Buenos Aires 1977.

BAUM, G., Los judíos y el Evangelio, Madrid 1965.

BEN-SASSON H. H., (Ed.), Historia del pueblo judío, Madrid 1991.

BenVENISTE, A., Le Bosphore à la Roquette: La communauté judéo-espagnole à Paris (1914-1940), Paris 1989.

Berman, A., Nazism: The Jews and American Zionism 1933-1948, Detroit 1990.

BRoWN, R. E., El nacimiento del Mesías, Madrid 1982.

Brown, R. E., La muerte del Mesías, T. I y T. II, Pamplona 2005 y 2006.

CANo, Ma J. - EsPinosa, M. A., Historia y cultura del pueblo judío, Granada 2008.

CARO, J., Síntesis del Shulján Aruj, Buenos Aires 1968.

CAVEro Coll, J. P., El pueblo judío en la Historia, política, sociedad, religión y cultura, Madrid 2014.

Barcelona 1963; E. C. SCHLESIngER, Tradiciones y costumbres judías, Buenos Aires 1970; P. VAN IMSCHOOT, Teología del Antiguo Testamento, Madrid 1969, pp. 461-541; J. DANIÉLOU, Sacramentos y culto, Madrid 1962. 
Concilio Vaticano II, “Declaración Nostra Aetate”, 4, en AAS 58 (1966) 740-744.

Chouraqui, A., Historia del judaísmo, Barcelona 1963.

Crouzel, H., Origène, Paris 1985.

Crown, A. D., "Redating the schism between the judaeans and the samaritans", en The Jewish Quarterly Rewiew LXXXII (July-October 1991) 17-50.

De VRIES, S. PH., Ritos y símbolos judíos, Madrid $2007^{2}$.

De LANGE, N. R. M., Judaísmo, Barcelona 1996, Madrid 2003 y 2006.

De LANGE, N., El judaísmo, Madrid 2000.

Del Valle, C., La Misná, Salamanca $2011^{2}$.

De la Maisonneuve, D., Le judaïsme, París 1984.

DE LUBAC, H., Histoire et Esprit. L'intelligence de l'Existence d'après Origène, Paris 1950.

Del Olmo Lete, G., Origen y persistencia del judaísmo, Estella (Navarra) 2009.

Del Valle, C., El mundo judío, Madrid 1978.

DANIÉLOU, J., Sacramentos y culto, Madrid 1962.

Deman, P., Los judíos, fe y destino, Andorra 1962.

Díaz-MAS, P. - De LA Puente, C., Judaísmo e islam, Barcelona 2007.

DION, P. E., Universalismo religioso de Israel, Estella (Pamplona) 1976.

EBAN, A., Mi pueblo, la historia de los judíos, Buenos Aires 1973.

Edersheim, A., La vida y los tiempos de Jesús el Mesías, Madrid 1989.

EQUIPO DE REDACCIÓN PAL, Historia de las religiones, Bilbao 1980.

EPSTEIN, I., Judaism. A Historical Presentation, Londres 1974.

FACKENHEIM, E. L., ¿QQué es el judaísmo?: una interpretación para nuestra época, Buenos Aires 2005.

GALBIATI, E., Exilio, retorno y judaísmo, Madrid 1985. 
GIRA, D., Las religiones, Bilbao 1994.

GILBERT, M., (Ed.), El Atlas Ilustrado de la civilización judía, Buenos Aires 1988.

GNILKA, J., Jesús de Nazaret: Mensaje e historia, Barcelona 1993; J. JeREMíAs, Jerusalén en tiempos de Jesús, Madrid 2000. 2007.

GoldenberG, R., The Origins of Judaism. From Canaan to the Rise of Islam, Cambridge

GoldBerG, D. - RAYNER, J., El pueblo judío, Londres 1987.

GoLDIN, J., La expresión judía, Londres 1976.

GonzÁlez-EChegaray, J., Flavio Josefo. Un historiador judío de la época de Jesús y de los primeros cristianos, Salamanca 2012, pp. 75-88.

GonzÁlez LAMADRID, A., Los descubrimientos del Mar Muerto, Madrid 1973.

GuerRa GómeZ, M., Historia de las religiones, Madrid 2010.

HertzBerg, A., Judaísmo, Barcelona 1963.

HERZL, T., El Estado Judío, Leipzig 1902, Wasghinton 1946, Barcelona 2005.

HeSCHE, A.J., Dios en la búsqueda del Hombre, Nueva York 1955;

JACOBS, L., God, Torah, Israel: Traditionalism without Fundamentalism, Cincinnati 1990.

JoHnson, P., La Historia de los judíos, Buenos Aires 1991.

KELLER, W., Historia del pueblo judío, Barcelona 1969.

KARFF, S. E., "Una respuesta a fundamentalismo judío contemporáneo", Concilium XXVIII (241:1992) 459-466.

KüNG, H., El judaísmo. Pasado, presente y futuro, Madrid 2013․

LAENEN, J. H., La mística judía. Una introducción, Madrid 2006.

MAIER, J., Das Judentum. Von der biblischen Zeit bis zur Moderne, Múnich 1973.

MAIER, J. - SCHÄFER, P., Diccionario de judaísmo, Estella (Navarra) 1996. 
Martín Escudero, F., "Calendario judío e islámico, ¿Dataciones exóticas en la península?", en J. C. Galende - J. De SANTIAgo FernÁndeZ, X Jornadas de Documentación. El calendario y la datación histórica, Madrid 2011, pp. 221-247: especialmente 234-236.

MartíneZ, J. M., “Fiestas judías”, en Tierra Santa 2 (№ 21: Enero-Febrero 2014) 6-9.

MARX, K., La cuestión judía, Buenos Aires 2004.

MATE, R. - FORSTER, R., El judaísmo en Iberoamérica, Madrid 2007.

Matzliah Melamed, M., El judaísmo, Madrid 1981.

Mitre FernándeZ, E., Judaísmo y cristianismo: raíces de un gran conflicto histórico, Madrid 1980.

NeUSNER J., La vida de la Torá: Lecturas en la experiencia religiosa judía, Belmont (California) USA 1974.

NEUSNER,J., El camino de la Torá, Belmont (California) USA 1988.

NeUSNER, J., Un rabino habla con Jesús, Madrid 2008; D. J. PLATA - B. MARTIN, Una historia del judaísmo, 2 Vols. Nueva York 1974.

NeUSNER, J., "El reto de fundamentalismo judío contemporáneo", en Concilium XXVIII (241:1992) 453-458.

NeWman, J. - Siván, G., Judaísmo de A-Z. Léxico ilustrado de términos y conceptos, Jerusalén 1983.

PenNA, A., La religión de Israel, Barcelona 1961.

Pereda Roig, C., Concordancia de los Calendarios de la Hégira y de la Era Cristiana, desde el año 1 de aquélla hasta el 2000 de ésta, Tetuán 1941.

ORIAN, M., Maimónides: vida, pensamiento y obra, Barcelona 1984.

PIKAZA, X. - AYA, A., Diccionario de las tres religiones. Judaísmo, cristianismo, Islam, Estella (Navarra) 2009.

RaVenNA, A., El hebraísmo postbíblico, Barcelona 1960.

RePETto Betes, J. L., Ecumene. Análisis de la controversia judaizante, Jerez de la Frontera (Cádiz) 1972.

Rodríguez Carmona, A., La religión judía. Historia y teología, Madrid 2001. 
SAMUEL, A., Para comprender las religiones en nuestro tiempo, Estella (Navarra) 2011.

SANDERS, E. P., Jesús y el judaísmo, Madrid 2004.

SIEBEN, H.-J., Einleitung zu Origenes. In Lucam homiliae, Freiburg 1991.

Sobel, Z. - Beit - Hallahmi, B., (Eds.), Tradición, Innovación, Conflicto: el judaísmo en Israel Contemporáneo, Nueva York 1991.

SCHOPEN, E., Historia del judaísmo en Oriente y Occidente, Alcoy (Alicante) 1970.

SCHLESINGER, E.C., Tradiciones y costumbres judías, Buenos Aires 1970.

SORJ, B., Judaísmo para todos, Río de Janeiro 2011.

Stein, R. H., Jesús el Mesías, Madrid 2008.

SUÁREZ FernáNDEZ, L., Los Judíos, Barcelona 2004.

TAPIA - AdLER, A. Mạ., Introducción al judaísmo, Santiago de Chile 2010.

TeStemalle, A. M., ¿'Silencio o ausencia de Dios? Ensayo sobre el problema de Dios en la obra de los pensadores judíos contemporáneos: Wiesel-Bloch-Neher, Madrid 1975.

TOAFF, R., La Nazione Ebrea a Livorna e a Pisa (1591-1700). Storia dell'ebraismo in Italia, Florencia 1990.

TOULAT, J., Los judíos, mis hermanos, Barcelona 1964;

Trebolle Barrera, J., El judaísmo moderno, Madrid 2001.

VAN IMSCHOOT, P., Teología del Antiguo Testamento, Madrid 1969.

Vidal Manzanares, C., Textos para la historia del pueblo judío, Madrid 1995.

Voderholzer, J., Henri de Lubac, Typologie-Allegorese-Geistiger Sinn, Freiburg 1999.

Voltaggio, F.G., Las fiestas judías y el Mesías, Madrid 2018.

WIGODER, G., Enciclopedia del judaísmo, Nueva York 1989.

WRIGHT, N. T., La resurrección del Hijo de Dios, Pamplona 2008.

\section{Webgrafía}


http://religionjudia.idoneos.com/ Visto 31-01-2016.

http://www.elconfidencial.com/sociedad/2016-01-31/los-nuevos-hijos-de-israel-asise-forman-los-judios-conver Visto 31-01-2016.

http://www.judiosyjudaismo.com/2013/01/la-importancia-de-entender-que-es-laliteratura-rabinica-mishna-guemara-talmud-y-midrash/ Visto 31-01-2016.

http://www.fiestajudia.com/ceremonias/ceremonia-copa.shtml Visto 31-01-2016.

http://lavozmesianicasefardita.blogspot.com.es/2011/07/el-jai-el-simbolo-de-lavida.html Visto 31-01-2016.

http://www.fiestajudia.com/consejos/simbolos-judios.shtml Visto 31-01-2016.

http://archive.feedblitz.com Visto 31-01-2016.

http://www.religionenlibertad.com/articulo.asp? Idarticul =23601 Visto 16-06-2013.

http://www.enfemenino.com/moda/las-bodas-judias-s448776.html Visto 16-122015.

http://www.fcje.org/ Visto 16-12-2015.

http://www.thebellmeade.com/costumbres-funerarias-judias-y-aceites-de-uncion/ Visto 31-01-2016.

https://www.cjmadrid.org/identidad-judia/ciclo-de-vida/fallecimiento Visto 31-012016.

http://www.rememori.com/pagina/rituales-judios-ante-el-fallecimiento Visto 31-012016.

http://www.redfuneraria.com/funeral-judio Visto 24-01-2016.

http://www.radiojai.com.ar Visto 30-01-2016.

http://www.mfa.gov.il/mfa/mfaes/facts\%20about\%20israel/pages/objetos\%20cerem oniales Visto 31-01-2016.

http://diccionario.sensagent.com/kipa/es-es/ Visto 31-01-2016.

http://www.franciscanos.org/selfran45/jornadapaz86.html Visto 31-01-2016. 